\title{
Caracterización genética de los primeros pobladores de los Andes nororientales en Colombia
}

\author{
Alberto Gómez-Gutiérrez \\ Instituto de Genética Humana, Facultad de Medicina, Pontificia Universidad Javeriana, Bogotá, D.C., Colombia \\ Artículo de posesión para el ingreso como miembro correspondiente de la \\ Academia Colombiana de Ciencias Exactas, Físicas y Naturales el 12 de julio de 2017
}

\begin{abstract}
Resumen
A partir del hallazgo y el estudio de objetos minerales transformados por las comunidades que habitaron la cordillera Nororiental de los Andes en tiempos precolombinos, sus restos humanos pueden analizarse hoy con las herramientas de la genética molecular aplicadas al ADN extraído de huesos y dientes de cada individuo. El presente texto presenta una síntesis de los trabajos publicados en los últimos diez años por el Instituto de Genética Humana de la Pontificia Universidad Javeriana de Bogotá, con base en el análisis del ADN de indígenas contemporáneos y precolombinos, en un rango de tiempo que sobrepasa los 6.000 años. Estos estudios han aportado precisiones sobre las dinámicas de circulación de los pobladores de la esquina noroccidental de Suramérica en el espacio y en el tiempo. Los nuevos hallazgos genéticos, conjugados con los conceptos aportados por la antropología y la arqueología sobre estas mismas comunidades, permitirán precisar factores determinantes como la diversidad y la filiación biológica de los diferentes grupos humanos que se han establecido en el territorio colombiano. (C) 2017. Acad. Colomb. Cienc. Ex. Fis. Nat.
\end{abstract}

Palabras clave: ADNmt; nativos americanos; Colombia; haplogroupos.

Genetic characterization of the first settlers of the North-Eastern Andes in Colombia

\begin{abstract}
Beyond the discovery and study of mineral objects transformed by the communities that inhabited the North-Eastern Andes in pre-Columbian times, human remains can be analyzed today with the tools of molecular genetics applied to DNA extracted from bones and teeth of each individual. The present text presents a synthesis of the works published in the past ten years by the Institute of Human Genetics at Pontificia Universidad Javeriana in Bogotá, based on the analysis of DNA of contemporary and pre-Columbian natives, in a time range of over 6,000 years. These studies have provided insights on the dynamics of circulation in space and over time of the settlers of the Northwest corner of South America. New genetic findings, coupled with concepts contributed by anthropology and archaeology on these same communities, will help to precise factors such as the diversity and biological affiliation of different human groups that have settled in the Colombian territory. (C) 2017. Acad. Colomb. Cienc. Ex. Fis. Nat.
\end{abstract}

Key words: mtDNA; Native Americans; Colombia; haplogroups.

\section{Introducción}

Las primeras evidencias de pobladores en el territorio que hoy comprende Colombia se han reportado en lugares tan distantes como la costa Caribe, el valle del río Magdalena, el altiplano cundiboyacense y el suroccidente del país (Correal, 1971, 1973; Friedemann \& Arocha, 1985; Botiva, 1989; Langebaek, 1992; Rodríguez, 2007; López-Castaño \& Cano-Echeverri, 2011; Delgado, 2012a; Delgado, 2012b; Aceituno, et al., 2013; Rodríguez \& Vargas, 2015; Delgado, 2017). La aparente escasez de restos humanos prehistóricos en las zonas costeras y en las zonas selváticas del Pacífico y de la Amazonía se debe, probablemente, a la exuberancia y mayor capacidad de descomposición orgánica de estos ecosistemas. Sin embargo, algunos vestigios culturales, como las pinturas rupestres de Chiribiquete, permiten postular que los primeros pobladores prehistóricos transitaron también por los territorios orientales, incluida la Orinoquía, más de 19.000 años antes del presente (a. P.).(Castaño-Uribe \& Van der Hammen, 1986).

En lo que tiene que ver con la sabana de Bogotá, investigaciones arqueológicas de contexto han permitido postular las primeras presencias humanas entre 10.000 y 12.000 años a. P. en los abrigos rocosos de Tequendama (Correal \& Van der Hammen, 1977; Neves, Hubbe \& Correal, 2007).

\footnotetext{
Correspondencia:

Alberto Gómez-Gutiérrez, agomez@javeriana.edu.co

Recibido: 12 de junio de 2017

Aceptado: 01 de noviembre de 2017
} 
Estos primeros grupos de cazadores y recolectores habrían ingresado al altiplano de los Andes orientales desde el valle del río Magdalena tras los pasos de los grandes animales cuyos restos se han hallado en estos mismos abrigos rocosos. De todos estos remanentes, los restos propiamente humanos más antiguos datados directamente hasta la fecha no sobrepasan una edad aproximada de $10.090 \pm 90$ años a. P. (Correal, 1979), es decir, cuatro mil años antes del resto humano más antiguo del Tequendama, hallado en Sueva, Cundinamarca, y fechado en el Groningen C14 Laboratorium de Holanda. A este le siguen hoy los restos humanos hallados en la vereda de Guavio, en la cordillera Oriental, y en la vereda de Checua, cercana al pueblo de Nemocón, con fechas aproximadas de 9.000 y 8.000 años a. P., respectivamente (Groot, 1992; Rodríguez, 2011; Sandoval \& Almanza, 2012; Delgado, 2012).

Estos restos humanos, evidencia primaria del poblamiento prehistórico, han sido estudiados con las herramientas clásicas de la antropología física, basadas esencialmente en la morfología de huesos y dientes que han resistido la degradación biológica a través del tiempo. Pero estas piezas macroscópicas no son las únicas evidencias orgánicas y antropológicas de que dispone la ciencia para estudiar las poblaciones prehistóricas. También el material biológico celular microscópico, así como el material molecular que este mismo contiene en su núcleo y en su citoplasma, pueden estudiarse hoy en el laboratorio para determinar el origen de cada resto (humano, animal o vegetal) asociado a estos hallazgos.

\section{EI ADN como recurso arqueológico}

Una de las moléculas que se hallan contenidas en cada célula del organismo es el ácido desoxirribonucléico (ADN), polímero de nucleótidos encadenados cuya secuencia varía en los diferentes individuos y en las diferentes especies. El $\mathrm{ADN}$ se encuentra tanto en el núcleo (ADN nuclear), como en las mitocondrias del citoplasma (ADN mitocondrial), y se ha demostrado que resiste el impacto del ambiente a lo largo del tiempo siempre y cuando esté conservado en los intersticios óseos y dentales de los remanentes orgánicos (Pääbo, 2004). Esta molécula, que contiene las instrucciones fundamentales para la organización y reproducción de cada ser vivo, se puede extraer, amplificar y secuenciar en el laboratorio.

La correspondencia directa entre la identidad de cada resto humano y las secuencias de los nucleótidos del ADN extraído de sus huesos y dientes se ha revelado mediante rigurosos métodos in vitro y por simulación computacional, convirtiéndose en fundamento de una nueva ciencia, la antropología genética o molecular, complementaria de la antropología física. La información obtenida con base en la morfología de restos óseos y dentales puede contrastarse hoy con las secuencias genéticas que estos contienen en el ADN. Estas secuencias, en razón de su filiación molecular con el resto de la especie y, en particular, con su linaje familiar, permiten individualizar y afiliar cada hallazgo individual con su parentela más cercana y con la más distante. Ahora bien, tres definiciones básicas de la genética de poblaciones son necesarias para la presente reflexión: el concepto de "clado", que representa el parentesco taxonómico en el árbol filogenético de todas las especies vivas; el concepto de "haplogrupo", que representa el parentesco intraespecífico (o familiar), y el concepto de "haplotipo", que representa la identidad individual.

La posibilidad de definir individualidades y parentescos a partir de las secuencias genéticas obtenidas del material biológico proveniente de los restos en excavaciones arqueológicas será la base de la presente reflexión académica, en la que se pretende hacer una aproximación a la evidencia genética de los primeros pobladores del territorio colombiano y, en particular, de la sabana de Bogotá, con base en algunos resultados moleculares preliminares en las poblaciones estudiadas en el Instituto de Genética Humana de la Universidad Javeriana en colaboración con antropólogos, arqueólogos y genetistas de diferentes universidades.

\section{Linajes genéticos en el ADN en América}

Las sociedades tradicionales se han organizado de diferentes maneras, incluidas, generalmente, subestructuras familiares denominadas "linajes", "clanes" o "tribus". Estas subdivisiones poblacionales se relacionan con un ancestro común, el cual distingue a cada grupo del resto de la población. En el caso que nos ocupa, los hallazgos directos obtenidos a partir del ADN de restos humanos indígenas prehistóricos, se pueden confrontar con las tipificaciones del $\mathrm{ADN}$ de individuos contemporáneos con ancestro indígena para conformar una base de datos ampliada que permita entender el origen del hombre americano.

Linajes maternos. Los hallazgos experimentales en el ADN han mostrado que, entre los diferentes marcadores moleculares de filiación o descendencia, cada individuo dispone de un patrimonio genético exclusivamente materno que está asociado a las mitocondrias citoplasmáticas del óvulo que lo origina, en tanto que se ha podido comprobar que al ingresar al óvulo en el momento de la fecundación, el ADN mitocondrial del espermatozoide, es decir el ADN mitocondrial paterno, activa un proceso de degradación lisosomal y se diluye hasta su eventual desaparición en medio de cientos de mitocondrias de origen materno en el óvulo fecundado (Sato \& Sato, 2013; Carelli, 2015). Así, las mitocondrias maternas pasan de generación en generación a través de las hijas de cada vínculo $\mathrm{y}$, en consecuencia, el linaje uniparental materno o mitocondrial podría coincidir con los linajes culturales de las sociedades matrilineales.

Linajes paternos. Existe también un patrimonio molecular exclusivamente paterno que está asociado al ADN del cromosoma Y que, como se sabe, es exclusivo del sexo masculino, cuyos cromosomas sexuales son el cromosoma $\mathrm{X}$ y el cromosoma $\mathrm{Y}$, mientras que los del sexo femenino son dos cromosomas $\mathrm{X}$. En este sentido, por definición, el patrimonio genético del cromosoma $\mathrm{Y}$ solo se hereda a los hijos varones y debería coincidir con los linajes culturales de las sociedades patrilineales. 
La exposición sobre la eventual correspondencia de los marcadores genéticos con referentes tan complejos como las subdivisiones culturales de todos y cada uno de los grupos humanos requiere, en este punto, ampliar la definición de dos de los tres elementos conceptuales de la genética de poblaciones que han permitido proponer una estructura taxonómica molecular en la especie humana: los "haplogrupos" y los "haplotipos" genéticos.

Haplogrupos genéticos. En diversos estudios genéticos poblacionales con marcadores uniparentales (el ADN mitocondrial, ADNmt, o el ADN del cromosoma Y, ADNcrY), se ha encontrado que determinados grupos genéticos compartían ciertos polimorfismos específicos y presentaban un origen común. Estos grupos genéticos se denominaron "haplogrupos", puesto que se referían a una parte del genoma que es haploide, pues no tiene contraparte parental (Torroni, et al., 1992), y se clasificaron con un código alfanumérico.
Una vez concertada la nomenclatura de este sistema de referencia molecular, se encontró que los haplogrupos mitocondriales humanos tenían un origen común y estaban distribuidos en el planeta con un patrón geográfico específico: los haplogrupos E, L1, L2, L3, M y N principalmente en África y Medio Oriente; los haplogrupos H, I, J, K, T, U, V y W en Europa y Medio Oriente; los haplogrupos P, Q, R y Z en Medio Oriente; los haplogrupos F, G, O, S e Y en Asia, Australia y Oceanía; los haplogrupos A, B, C, y D en Asia y en nativos americanos, y el haplogrupo X en Europa, Medio Oriente y en un pequeño número de nativos norteamericanos (Van Oven \& Kayser, 2008) (Figuras 1 y 2).

Otro tanto sucedió con los marcadores uniparentales paternos del cromosoma Y, para los cuales también se dispone de un mapa con el origen de cada haplogrupo y con las rutas de migración global de cada uno de ellos en el planeta (Figura 3).

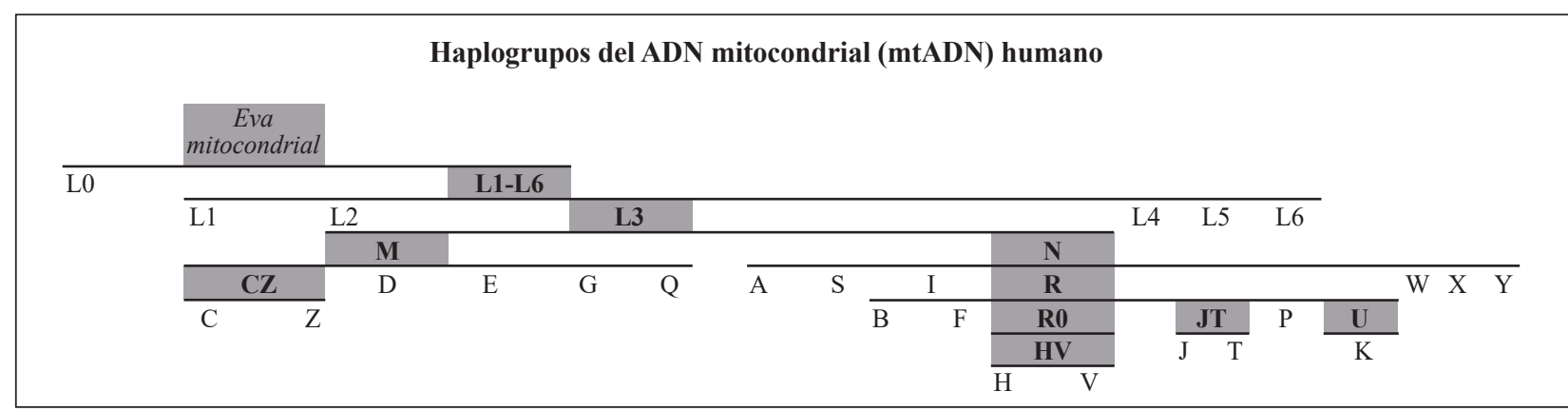

Figura 1. Relación ancestral de los haplogrupos en el ADN mitocondrial humano

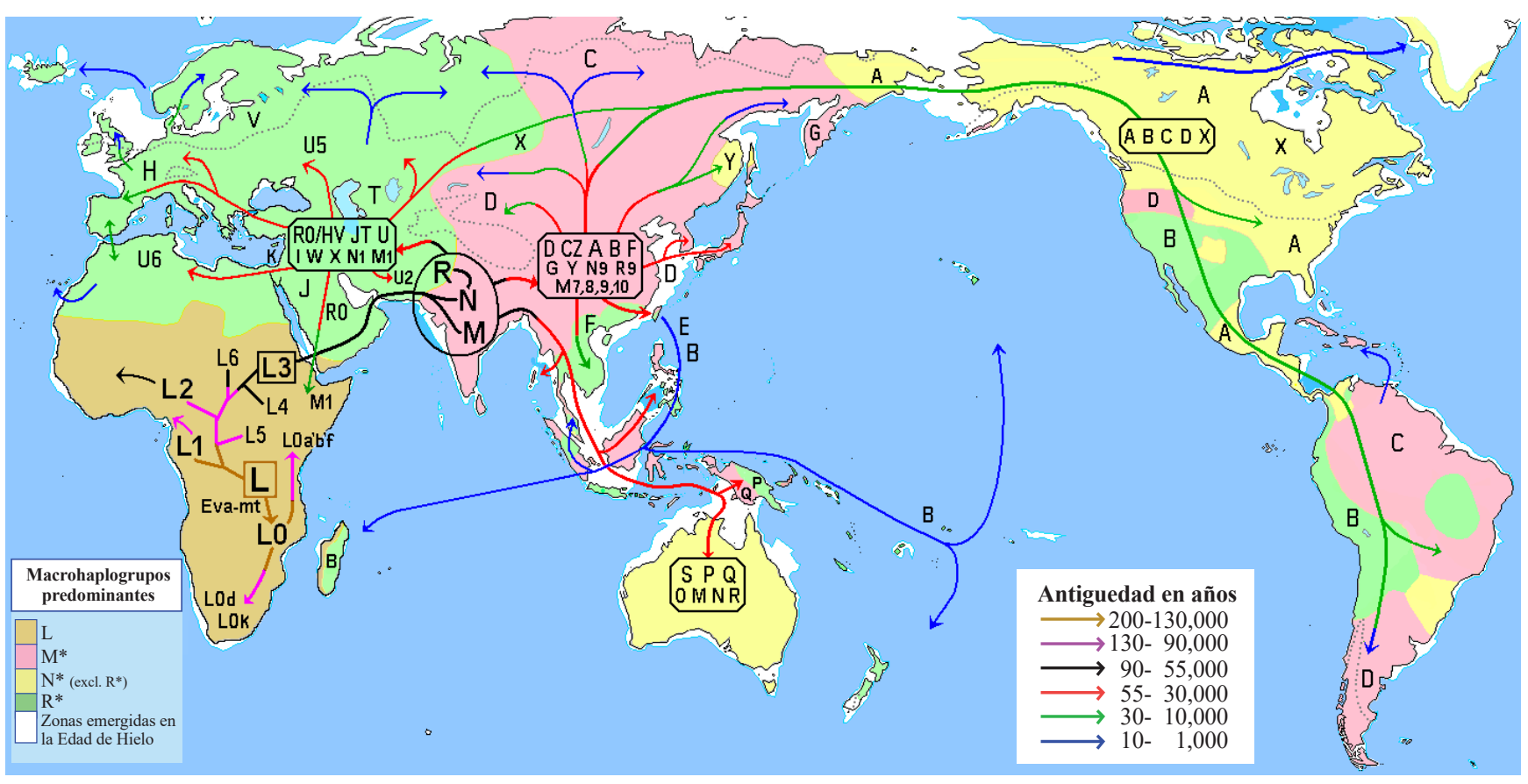

Figura 2. Migración de las poblaciones humanas según los marcadores o haplogrupos del ADN mitocondrial. Tomado de: Wikimedia Commons, http://es.wikipedia.org 


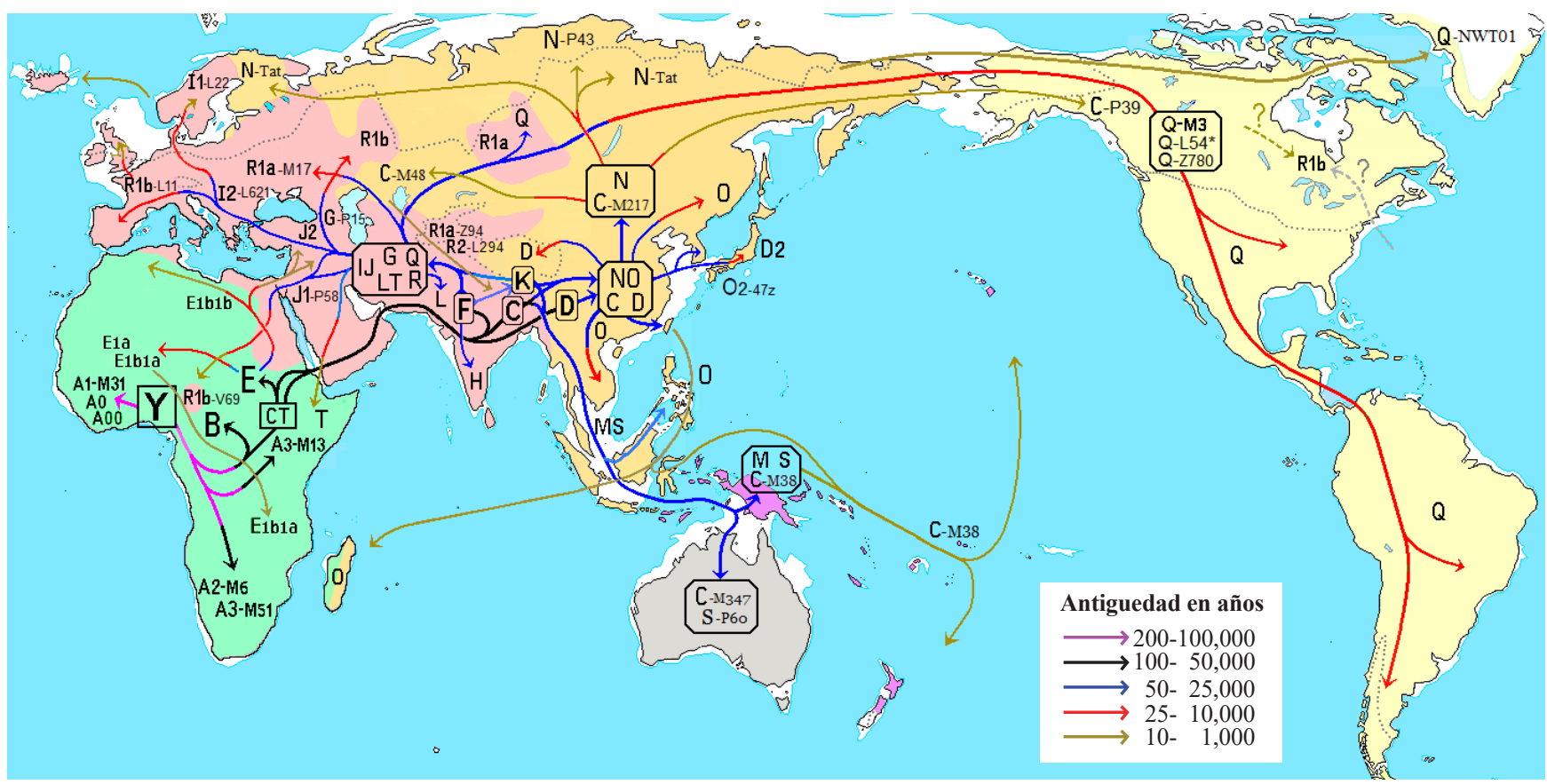

Figura 3. Migración de las poblaciones humanas según los marcadores o haplogrupos del cromosoma Y. Tomado de: Wikimedia Commons, http://es.wikipedia.org

Con base en estos patrones de distribución, se concluyó que los haplogrupos mitocondriales y los haplogrupos del cromosoma $\mathrm{Y}$ exhiben una filiación que fue específica de continente $\mathrm{y}$, en consecuencia, se han convertido en una herramienta útil para los estudios de poblamiento y de los procesos de microevolución que han resultado de las migraciones humanas a través de los diferentes ecosistemas del planeta. En este orden de ideas, se ha propuesto para todos los linajes indígenas americanos contemporáneos al menos un ancestro común paterno mayoritario en el cromosoma $\mathrm{Y}$ del ADN nuclear (Pena, et al., 1995; Battaglia, et al., 2013), así como cinco ancestros comunes maternos principales en las regiones hipervariables del ADN mitocondrial (Torroni, et al., 1993; Shurr, et al., 1990; Achilli, et al., 2008). Se ha podido calcular que estos hipotéticos ancestros comunes habitaban en el territorio siberiano hace más de 22.000 años, y se postula que un grupo de sus descendientes habría pasado al continente americano en los tiempos de la última edad de hielo (o glaciación de Würm/Wisconsin), cuyo periodo máximo se ha datado aproximadamente entre $16.000 \mathrm{y}$ 20.000 años a. P. (Goebel, et al., 2008; Dulik, et al., 2012; Santos, et al., 2012).

Debe resaltarse que otras aproximaciones científicas han postulado también ancestrías indígenas comunes a partir de, por ejemplo, el estudio de las lenguas americanas contemporáneas (Greenberg, 1986). Es significativo y útil saber que la aproximación lingüística se asemeja en forma y fondo a la aproximación genética, por cuanto ambas se basan en la comparación y proyección de secuencias combinatorias de letras (en el caso de los nucleótidos del ADN: 4 letras diferentes, A, T, G y C, correspondientes a los nucleótidos adenina, timina, guanina y citosina). En ambos casos, los cambios puntuales o en bloque, cuya coalescencia (o coincidencia ancestral) ha sido demostrada, refieren a un origen siberiano para los primeros pobladores del nuevo continente.

Haplotipos genéticos. Cada haplogrupo genético, tanto mitocondrial como cromosómico, se caracteriza por una serie de mutaciones principales, o mutaciones consenso, que lo hacen diferente de los demás pero, a su vez, contiene un número indefinido de mutaciones específicas de un mismo haplogrupo que pueden servir para caracterizar a cada sublinaje en cada población estudiada. La suma individual de estas mutaciones subespecíficas recibe el nombre de "haplotipo" genético, el cual puede llegar a identificar linajes familiares individuales en el seno de cada comunidad.

Así, al presentar estudios moleculares poblacionales, se deberán considerar al menos dos niveles de resolución: un nivel macro de haplogrupos, que reúne a todo el clan, y un nivel micro que reúne cada linaje o cada familia. En síntesis, los miembros de un haplogrupo determinado pueden o no pertenecer a la misma familia o linaje, a la manera de los clanes escoceses o, en nuestro medio, de los individuos que comparten un apellido con ancestro común debidamente documentado o probado.

\section{Proyección ancestral de los estudios moleculares en indígenas contemporáneos}

Ya se mencionó en la introducción que el ADN podía conservarse a través de los siglos en los intersticios de huesos y dientes. Sin embargo, debe considerarse que el ADN de cada 
ser humano también se conserva con muy pocas mutaciones, de manera íntegra y funcional, en los descendientes de cada individuo gracias a los mecanismos de duplicación celular que prolongan las especies vivas generación tras generación, con una particularidad: en términos generales (con la única excepción de una pequeña región terminal del cromosoma Y), ni el ADN mitocondrial (ADNmt) ni el ADN del cromosoma $\mathrm{Y}$ (ADNcrY) recombinan los genes que contienen, como sí sucede con el ADN nuclear en los 22 pares de cromosomas restantes y en el cromosoma X. Esta característica, es decir, la ausencia relativa de recombinación en el ADNmt y en el ADNcrY en cada generación, hace que se pueda proyectar confiablemente al pasado la información obtenida en este tipo de ADN en poblaciones actuales y, por lo tanto, que se puedan hacer predicciones suficientemente sólidas sobre la composición hipotética del ADN ancestral hasta los primeros pobladores de cada continente.

Por esta razón, las tipificaciones del ADN de individuos contemporáneos con ancestro indígena se han podido utilizar para conformar una base de datos que permite comprender el origen genético del hombre americano y, con base en trabajos deductivos, se han propuesto los ancestros comunes paternos y maternos de los linajes indígenas americanos contemporáneos estudiados con las herramientas de la genética molecular.

A finales del siglo pasado, como se dijo, los ADNmt de indígenas nativos americanos se reducían a cuatro haplogrupos principales de origen asiático compartidos por poblaciones de Norteamérica, Centroamérica y Suramérica (Tamm, 2007). Estos haplogrupos "panamericanos" fueron inicialmente denominados A, B, C y D, y hoy presentan un gran número de 'sub-haplogrupos' a partir de la primera división en la que se describieron como A2, B2/4, C1/4 y D2/4. A partir de ellos se han propuesto decenas de nuevos sublinajes o clados (véase el portal http://www.phylotree.org) en función de los hallazgos en individuos de las diferentes poblaciones indígenas estudiadas hasta la fecha, con lo cual se han configurado troncos poblacionales moleculares provisionales para la totalidad de los indígenas americanos prehistóricos y contemporáneos (Perego, et al., 2010; BissoMachado, et al., 2012). Se ha incluido, además, por lo menos un quinto linaje, el linaje X2a, que es minoritario en Norteamérica y se encuentra principalmente en las regiones de los Grandes Lagos, de las Grandes Planicies y en el Pacífico noroeste (Reidla, et al., 2003). Recientemente, con base en la presencia de uno de los 22 sublinajes referidos, a los cuales se añadieron los macrolinajes A2, B2, D1 y $\mathrm{M}$, se propuso la configuración de un panel de genotipificación específico para determinar la ancestría americana (Coutinho, et al., 2014).

Por su parte, los linajes masculinos representados por los marcadores del cromosoma Y presentan en América una predominancia de lo que se ha denominado el macrohaplogrupo Q panamericano (Battaglia, et al., 2013). Veamos un ejemplo de la utilidad de los haplogrupos y haplotipos genéticos maternos o mitocondriales en el estudio del poblamiento americano y de su eventual origen. Al analizar en indígenas contemporáneos 69 genomas mitocondriales completos para dos de los sublinajes o haplogrupos menores particulares, el haplogrupo D4h3 y el haplogrupo X2a, se encontró que el sub-haplogrupo D4h3a, detectado con poca frecuencia en poblaciones modernas y antiguas de Norteamérica y Suramérica, aparecía geográficamente limitado a poblaciones que habitan la costa Pacífica, en tanto que el sub-haplogrupo D4h3b, emparentado estrechamente con el primero de estos haplogrupos, se ha localizado en la China (Perego, et al., 2009), lo cual revela la conectividad transcontinental de esta familia genética.

Otro ejemplo significativo en el estudio molecular de poblaciones indígenas contemporáneas, es el que resulta de los metaanálisis de marcadores genéticos uniparentales reportados en amerindios colombianos (Mesa, et al., 2000) o suramericanos (Bisso-Machado, et al., 2012). En un extracto de la tabla publicada por estos últimos autores, en la que relacionaron los haplogrupos mitocondriales (es decir, los linajes maternos) de 6.697 individuos pertenecientes a 109 comunidades indígenas suramericanas, se puede constatar que casi la mitad de estas (3.266 individuos en 50 comunidades), hoy asentadas entre los 11 grados de latitud norte y los 4 grados de latitud sur (Bisso-Machado, et al., 2012), presentan los siguientes porcentajes de cada uno de los haplogrupos nativos americanos: $28,4 \%$ de los linajes maternos pertenecen al haplogrupo $\mathrm{A} ; 24,6 \%$, al haplogrupo B; 28,5 \%, al haplogrupo C, y 14,9\%, al haplogrupo D, para un total de $96,4 \%$ perteneciente a haplogrupos maternos característicos de los amerindios en estas poblaciones. El 3,6\% restante pertenece a otros haplogrupos, es decir a haplogrupos no americanos, lo cual es evidencia del mestizaje con otras poblaciones que migraron a América en tiempos poscolombinos. Estos mestizajes no son generales y se presentaron con mayor frecuencia (en 12 a $59 \%$ de sus miembros) en los grupos Guahibo, Guayabero, Awa-Juriti, Piapoco y Sáliba (Tabla 1).

Por el contrario, los resultados correspondientes a los haplogrupos del cromosoma Y (es decir, a los linajes paternos) evaluados en 590 individuos pertenecientes a 29 comunidades diferentes, mostraron un porcentaje mayor de mestizaje con haplogrupos no amerindios. En efecto, para el mismo rango de latitudes (entre $\operatorname{los} 11^{\circ} \mathrm{N}$ y $\operatorname{los} 4^{\circ} \mathrm{S}$ ), se reportó $50 \%$ con el macrohaplogrupo $\mathrm{Q}$, mayoritariamente amerindio, y $50 \%$, con haplogrupos no amerindios provenientes de mestizajes con inmigrantes masculinos poscolombinos, lo que está claramente relacionado con un aporte no amerindio de origen paterno.

Un tercer ejemplo de la proyección de los estudios genéticos contemporáneos como fundamento de la composición genética y filiación de los primeros pobladores en Colombia, lo constituye nuestro trabajo colaborativo con el Departamento de Antropología de la Universidad de Kansas sobre la relación biológica entre las poblaciones de 
Tabla 1. Haplogrupos mitocondriales en indígenas modernos del norte de Suramérica

\begin{tabular}{|c|c|c|c|c|c|c|}
\hline \multirow[t]{2}{*}{ Población } & \multirow[t]{2}{*}{ n } & \multicolumn{5}{|c|}{ Haplogrupo (\%) } \\
\hline & & $\mathbf{A}$ & B & $\mathbf{C}$ & D & Otros \\
\hline Wayuu & 89 & 26 & 28 & 45 & 0 & 1 \\
\hline Kogi & 153 & 67 & 0 & 33 & 0 & 0 \\
\hline Arsario (Wiwa) & 76 & 63 & 0 & 37 & 0 & 0 \\
\hline Chimila & 35 & 88 & 0 & 3 & 6 & 3 \\
\hline Arhuaco (Ijka) & 134 & 87 & 1 & 12 & 0 & 0 \\
\hline Yukpa & 88 & 0 & 100 & 0 & 0 & 0 \\
\hline Zenú & 107 & 19 & 38 & 36 & 5 & 2 \\
\hline Embera & 43 & 53 & 35 & 2 & 5 & 5 \\
\hline Tule (Cuna) & 30 & 50 & 27 & 20 & 0 & 3 \\
\hline [Guane] & 33 & 12 & 64 & 0 & 24 & 0 \\
\hline Cubeo & 22 & 27 & 18 & 50 & 5 & 0 \\
\hline Makiritare & 10 & 20 & 0 & 70 & 10 & 0 \\
\hline Kali'na (Galibi) & 29 & 7 & 41 & 38 & 7 & 7 \\
\hline Guahibo & 99 & 52 & 3 & 33 & 0 & 12 \\
\hline Waunana & 161 & 21 & 49 & 16 & 14 & 0 \\
\hline Palikur & 64 & 1 & 47 & 4 & 47 & 1 \\
\hline Makushi & 10 & 10 & 20 & 30 & 40 & 0 \\
\hline Páez & 51 & 59 & 12 & 27 & 2 & 0 \\
\hline Piaroa & 28 & 36 & 11 & 21 & 32 & 0 \\
\hline Wapishana & 12 & 0 & 25 & 8 & 67 & 0 \\
\hline Emerillon & 30 & 30 & 70 & 0 & 0 & 0 \\
\hline Guambioano & 23 & 4 & 4 & 79 & 13 & 0 \\
\hline Yanomami & 491 & 2 & 25 & 50 & 19 & 4 \\
\hline Guayabero & 30 & 50 & 17 & 13 & 0 & 20 \\
\hline Curripaco & 22 & 41 & 36 & 23 & 0 & 0 \\
\hline Tiriyó & 32 & 9 & 19 & 22 & 47 & 3 \\
\hline Nukak & 20 & 0 & 20 & 80 & 0 & 0 \\
\hline Apalai & 120 & 37 & 1 & 30 & 32 & 0 \\
\hline Cayapa & 120 & 29 & 40 & 9 & 22 & 0 \\
\hline Wayampi & 99 & 62 & 11 & 8 & 19 & 0 \\
\hline Siona & 12 & 75 & 17 & 8 & 0 & 0 \\
\hline Pasto & 9 & 67 & 33 & 0 & 0 & 0 \\
\hline Yagua & 12 & 25 & 0 & 67 & 8 & 0 \\
\hline Ingano & 111 & 18 & 38 & 42 & 0 & 2 \\
\hline Tucano & 17 & 0 & 18 & 47 & 35 & 0 \\
\hline Coreguaje & 69 & 4 & 20 & 66 & 6 & 4 \\
\hline Awa-Juriti & 18 & 0 & 72 & 11 & 0 & 17 \\
\hline Muinane & 19 & 11 & 21 & 37 & 26 & 5 \\
\hline Poturujara & 23 & 44 & 0 & 26 & 30 & 0 \\
\hline Katuena & 23 & 26 & 9 & 35 & 30 & 0 \\
\hline Wai-wai & 26 & 15 & 15 & 43 & 27 & 0 \\
\hline Urubu-Kaapor & 42 & 21 & 31 & 14 & 29 & 5 \\
\hline
\end{tabular}

\begin{tabular}{lrrrrrr} 
Huitoto & 35 & 23 & 3 & 25 & 46 & 3 \\
Arará & 70 & 54 & 20 & 26 & 0 & 0 \\
Awa-Guajá & 53 & 13 & 87 & 0 & 0 & 0 \\
Asurini & 24 & 4 & 54 & 17 & 21 & 4 \\
Piapoco & 39 & 18 & 3 & 15 & 5 & 59 \\
Puinave & 19 & 5 & 16 & 58 & 16 & 5 \\
Sáliba & 13 & 15 & 0 & 55 & 15 & 15 \\
Ticuna & 371 & 20 & 11 & 35 & 33 & 1 \\
Total & 3.266 & 28,4 & 24,6 & 28,5 & 14,9 & 3,6 \\
\hline
\end{tabular}

Nota. Tabla modificada a partir de Bisso-Machado, et al., 2012. No se incluyen las comunidades con menos de nueve individuos.

Centroamérica y Suramérica con base en su composición genética mitocondrial (Melton, et al., 2007). En este trabajo se analizaron muestras de ADN de 188 indígenas contemporáneos pertenecientes a tres comunidades de lengua chibcha (Kogui, Arsario, Ijka) y una comunidad de lengua arawak (wayuu) en el extremo norte de Colombia, y se determinó su relación biológica con otras comunidades de lengua chibcha.

Con los resultados de esta investigación molecular, se pudo demostrar una estructura genética compartida por los grupos de la Sierra Nevada de Santa Marta y las poblaciones maya centroamericanas, lo cual sugiere una temprana expansión de norte a sur de poblaciones centroamericanas de lengua chibcha, eventualmente asociada a estrategias de subsistencia frente a cambios en las condiciones ecológicas en esa región durante la transición entre el Pleistoceno y el Holoceno, que habrían tenido lugar 10.000 a 14.000 años a. P. Este hallazgo fue posteriormente confirmado por una de las estudiantes doctorales del Instituto de Genética Humana mediante un nuevo análisis del ADN mitocondrial en 700 individuos contemporáneos de 20 poblaciones nativas de Colombia (Noguera-Santamaría, et al., 2015). En cambio los indígenas wayuu, a pesar de su cercanía geográfica con los indígenas de la Sierra Nevada, resultaron muy distantes genéticamente de estas comunidades de lengua chibcha y muy cercanos en su ADN mitocondrial a comunidades amazónicas como los Yanomamo, lo que revela, asimismo, un posible patrón de poblamiento diferente para este macrogrupo.

Por último, en una aproximación al poblamiento de Colombia con base en marcadores moleculares, el programa "Expedición Humana" del Instituto reportó las frecuencias de los haplogrupos A, B, C y D en 25 comunidades indígenas diferentes (Keyeux, et al., 2002). La distribución actual de estos haplogrupos mitocondriales es la base de la propuesta sobre dos rutas diferentes de poblamiento en Suramérica, por cuanto el haplogrupo D es relativamente escaso en poblaciones mesoamericanas y está bien representado en comunidades indígenas que habitan al oriente del territorio. Así, habría habido una primera ruta de poblamiento a lo largo de la costa Pacífica, y una ruta alterna posterior de 
poblamiento a través del collar de islas del Caribe, ruta esta que podría haber sido bidireccional en diferentes momentos de la historia (Keyeux \& Usaquén, 2006).

\section{Troncos fundadores de los indígenas contemporáneos en el ADN moderno y antiguo}

La mayoría de los estudios citados hasta este punto se han llevado a cabo en muestras de individuos contemporáneos denominados "indígenas", o que así se autodenominan por tradición cultural o familiar, todos ellos de finales del siglo XX o comienzos del siglo XXI. Con base en su ADN se han proyectado las secuencias obtenidas a los troncos fundadores de los haplogrupos referidos. El ADNmt de estos 22 sub-haplogrupos identifica hoy de manera aparentemente completa el ancestro materno amerindio de todos los indígenas americanos; los 22 sub-haplogrupos presentan subdivisiones propiamente familiares e individuales denominadas haplotipos. Cada uno de los miembros de un haplogrupo puede pertenecer o no a la misma subfamilia o clan, con subdivisiones que, como ya se mencionó, recuerdan los clanes paternos escoceses.

En consecuencia, la mayoría de hipótesis alternativas acerca del poblamiento americano se han basado en predicciones más o menos fundamentadas sobre el pasado, así como en la coalescencia de los linajes estudiados y de los haplogrupos y haplotipos identificados en individuos denominados, en términos operativos, como individuos indígenas modernos (Tamm, et al., 2007; Reich, et al., 2012; Achilli, et al., 2013).

En el estudio de las primeras poblaciones del continente americano es posible hacer deducciones moleculares $\mathrm{y}$ proyecciones al pasado con base en el ADN conservado in vivo en sus descendientes, $\mathrm{y}$, además, tipificar directamente el ADN extraído de restos óseos antiguos de los indígenas precolombinos. Ello ha permitido desarrollar un panorama, ya no indirecto sino directo, de la identidad y de la filiación hipotética de los primeros pobladores americanos. En las siguientes secciones se tratan específicamente los hallazgos de tipificación molecular de muestras precolombinas en el contexto americano, y se presentan los hallazgos reportados en Colombia por nuestro grupo de investigación.

\section{Estudios moleculares en restos óseos de indígenas precolombinos en Colombia}

Para comenzar, es importante recordar que los haplotipos genéticos que identifican a cada individuo en la comunidad varían entre sí, esencialmente en razón de las mutaciones que se acumulan en el genoma a través del tiempo. Estas mutaciones permiten afiliar a su portador a linajes familiares de mayor o menor antigüedad en función del momento de aparición de la mutación correspondiente. En consecuencia, la identificación molecular de un haplotipo determinado en restos humanos precolombinos permite confirmar de manera cierta y directa su presencia en una región específica del continente americano, así como fundamentar la eventual continuidad de su linaje a través del tiempo mediante la comparación con haplogrupos y haplotipos modernos que se hayan reportado en la misma zona o en otras diferentes y, en ocasiones, muy distantes.

Restos óseos paleoamericanos. El universo disponible de restos humanos precolombinos en América es relativamente reducido, y mucho más escaso el conjunto de restos óseos paleoamericanos comparado con el universo disponible en los genomas contemporáneos de los eventuales descendientes de los primeros pobladores, cuya composición se comentó en la sección anterior. La Tabla 2 presenta los principales referentes arqueológicos paleoamericanos que han sido reportados en Suramérica, entre ellos el trabajo de Marcela Díaz-Matallana, estudiante doctoral de nuestro equipo (Díaz-Matallana, et al., 2014, 2016), en los restos humanos de la cultura checua, cuya excavación arqueológica fue coordinada en 1991 por Ana María Groot en Nemocón, departamento de Cundinamarca, y que correspondía al asentamiento de cazadores y recolectores en una secuencia cultural entre 8.500 y 3.000 años a. P. (Groot, 1992).

La datación directa de restos óseos pertenecientes a este hallazgo, así como la datación estratigráfica de los elementos de contexto, permite postular al menos dos niveles de ocupación humana que corresponden a la zona I, CHI (8.200 \pm 110 años a. P.), y a la zona II, CHII (7.800 \pm 160 años a. P.).

La exitosa extracción, amplificación y tipificación molecular del ADN mitocondrial de siete individuos de la zona I y de cuatro de la zona II (véase el electroferograma de la Figura 4 como evidencia de la calidad de las tipificaciones logradas a partir del ADN antiguo de este hallazgo), evidenció una gran diversidad humana en este asentamiento, pues en la zona más antigua $(\mathrm{CHI})$ se inhumaron individuos pertenecientes a cuatro linajes maternos diferentes: A2, B2, C1 y D4, y en la zona más reciente (CHII), individuos pertenecientes a los linajes A2 y B2, representados por un total de siete haplotipos o líneas familiares diferentes, lo cual contradice la idea tradicional de que se trataba de grupos aislados muy poco diversos (Tabla 3 ).

La diversidad de los haplogrupos encontrados en este pequeño asentamiento paleoamericano en la sabana de Bogotá podría implicar que el número de sus pobladores era mayor del previsto $y$, por otra parte, muestra bien la continuidad en el tiempo de algunos haplotipos, es decir de algunas líneas familiares, puesto que se hallaron individuos con haplotipos idénticos en las dos zonas estratigráficas en un rango de tiempo de cerca de 700 años, entre 8.310 y 7.640 años a. $P$.

Al comparar estos haplogrupos paleoindios con los haplogrupos modernos en la población mestiza del departamento de Cundinamarca, se evidenció, asimismo, una continuidad genética global en los haplogrupos A2, B2 y $\mathrm{C} 1$, y una aparente desaparición del haplogrupo D4, en particular del subclado D4h3a, en esta región. Este último subclado, hallado en uno de los restos óseos de los checua, se 
Tabla 2. Restos óseos paleoamericanos en Suramérica

\begin{tabular}{|c|c|}
\hline Lugar y hallazgo arqueológico & Rango cronológico (a. P.) \\
\hline $\begin{array}{l}\text { Cundinamarca, Colombia } \\
\text { - Tocaima }\end{array}$ & 12.000 \\
\hline $\begin{array}{l}\text { Cundinamarca, Colombia } \\
\text { - Sueva } 1\end{array}$ & $10.090 \pm 90^{3}$ \\
\hline $\begin{array}{l}\text { Gachalá-Cundinamarca, Colombia } \\
\text { - Guavio } 1\end{array}$ & $9.360 \pm 45^{3}$ \\
\hline $\begin{array}{l}\text { Cundinamarca, Colombia } \\
\text { - Tequendama } 1 \text { y } 2\end{array}$ & $9.740 \pm 135^{3}$ \\
\hline $\begin{array}{l}\text { Nemocón-Cundinamarca, Colombia } \\
\text { - Checua }\end{array}$ & $8.500-3.000^{2 a}$ \\
\hline $\begin{array}{l}\text { Cundinamarca, Colombia } \\
\text { • Chía III }\end{array}$ & $5.040 \pm 100$ \\
\hline $\begin{array}{l}\text { Soacha-Cundinamarca, Colombia } \\
\text { - Aguazuque }\end{array}$ & $5.030 \pm 40^{3}$ \\
\hline $\begin{array}{l}\text { Mosquera-Cundinamarca, Colombia } \\
\text { - Vistahermosa }\end{array}$ & $3.410 \pm 35$ a $3.135 \pm 35$ \\
\hline $\begin{array}{l}\text { Boyacá, Colombia } \\
\text { • Floresta }\end{array}$ & $7.950 \pm 40^{3}(7.040$ a 6.680 cal. $)$ \\
\hline $\begin{array}{l}\text { Lagoa Santa, Brasil } \\
\text { • Lapa Vermelha IV: “Luzia” }\end{array}$ & $10.030 \pm 60^{3}$ \\
\hline $\begin{array}{l}\text { Lagoa Santa, Brasil } \\
\text { • Cerca Grande 2, 5, y } 6\end{array}$ & $8.500-8.000$ \\
\hline $\begin{array}{l}\text { Brasil } \\
\text { • Región Amazónica }\end{array}$ & $4.000-500$ \\
\hline $\begin{array}{l}\text { Valle Chacama, Perú } \\
\text { • Huaca Prieta }\end{array}$ & $14.200-13.300^{3}$ \\
\hline $\begin{array}{l}\text { Argentina noroccidental (Puna) } \\
\text { • Antofagasta de la Sierra }\end{array}$ & $9.500-3.500$ \\
\hline $\begin{array}{l}\text { Pampas argentinas } \\
\text { - Arroyo Seco 2, Chocorí y La Tigra }\end{array}$ & $\sim 8.000$ \\
\hline $\begin{array}{l}\text { Norte de Chile } \\
\text { - LLuta, Azapa y Camarones }\end{array}$ & $6.000-500$ \\
\hline $\begin{array}{l}\text { Monte Verde, Chile } \\
\text { - Pre-Clovis }\end{array}$ & 14.600 \\
\hline $\begin{array}{l}\text { Chile } \\
\text { - Tierra del Fuego }\end{array}$ & $4.500-500$ \\
\hline
\end{tabular}

${ }^{1}$ Edad AMS exacta. ${ }^{2}$ Edad estratigráfica. ${ }^{2 a}$ Checua, datado inicialmente mediante estratigrafía; posteriormente, algunos individuos, gasterópodos y carbón se han datado mediante ${ }^{14} \mathrm{C}$ (Minelli, et al., 2012; Neves, et al., 2007), y resonancia paramagnética electrónica (EPR) (Sandoval \& Almanza, 2012). ${ }^{3}$ Datación mediante ${ }^{14} \mathrm{C}$. Tabla modificada a partir de Díaz-Matallana, et al., 2016

considera un marcador raro por cuanto solo ha sido reportado en algunos individuos paleoamericanos (Kemp, et al., 2007; Cui, et al., 2013; Rasmussen, et al., 2014; Bolnick, et al., 2014; Díaz-Matallana, 2014; Díaz-Matallana, et al., 2016), en individuos precolombinos de Tierra del Fuego (GarcíaBour, et al., 2004), en nativos americanos modernos en Argentina y Chile (De Saint-Pierre, et al., 2012) y, en un solo individuo mestizo de Bogotá (Bryc, et al., 2010).

Restos óseos precolombinos recientes. Una vez descritos los hallazgos moleculares en restos óseos de la cultura checua de la sabana de Bogotá, se presentan los sucesivos resultados moleculares obtenidos en los hallazgos de comunidades precolombinas más recientes: a) en el periodo Formativo temprano, cerca de 2.000 años a. P., en las inmediaciones de la laguna de la Herrera al suroccidente de la sabana de Bogotá (Silva, et al., 2008); b) en el periodo Muisca temprano (Jara, et al., 2010), cerca de 800 años a. P., al suroriente de la sabana de Bogotá; c) en el periodo Muisca tardío, entre 500 y 8.000 años a. P., en los territorios de la cultura guane al nororiente de Colombia (Casas-Vargas, et al., 2011). Se presentan, asimismo, los resultados preliminares de dos trabajos suplementarios aún en curso en restos óseos de los entierros muiscas de la zona del Templo del Sol en Sogamoso, Boyacá (Figura 5) (Casas-Vargas, et al., 2017).

a) Período Formativo temprano. Se analizaron 11 individuos pertenecientes al yacimiento arqueológico Madrid 2-41, de una edad aproximada de 2.000 años, mediante la amplificación y secuenciación de un fragmento de ADNmt de 192 pares de bases (pb) o nucleótidos en el segmento hipervariable I, siguiendo criterios estrictos de autenticidad del ADN arcaico. Las secuencias se compararon con secuencias existentes en bases de datos de Norteamérica y Europa mediante herramientas bioinformáticas. Las 11 secuencias resultaron idénticas y fueron clasificadas como pertenecientes al haplogrupo $\mathrm{B}$, lo cual puede relacionarse con el tipo de entierro ritual practicado en Madrid 2-41, es decir que los individuos analizados probablemente hicieran parte de una familia jerárquicamente importante en esta antigua sociedad y estaban vinculados por filiación materna. La búsqueda de secuencias homólogas en las bases de datos estadounidense y europea no arrojó coincidencias exactas, aunque existe el reporte de un individuo amazónico de cerca de 4.000 años de antigüedad reportado en Brasil cuya secuencia coincide con la hallada en Madrid 2-41. En conclusión, los individuos del yacimiento arqueológico Madrid 2-41, referido generalmente como perteneciente a la cultura Herrera en razón de su localización en torno a la laguna del mismo nombre, estaban estrechamente emparentados entre sí por línea materna y presentaron una secuencia aparentemente ausente en poblaciones actuales en el resto de América (Silva, et al., 2007).

b) Periodo Muisca temprano. Se tipificó el ADNmt de un total de 24 muestras óseas provenientes del rescate arqueológico de la Avenida Villavicencio en el barrio Candelaria La Nueva al suroriente de Bogotá, y en una primera aproximación global se encontró que todas ellas compartían el haplogrupo A (Jara, et al., 2010). Posteriormente, estas mismas muestras se analizaron con mayor detalle para definir sus haplotipos (Sánchez, 2007), y se encontró que todas las muestras menos una presentaban un haplotipo común en el haplogrupo A2. El individuo diferente en este mismo haplogrupo presentaba una mutación privada (adenina por guanina) en la posición 16213 del ADN mitocondrial, mutación que se puede utilizar como referencia para identificar su linaje familiar y que es relativamente frecuente en los actuales habitantes del altiplano cundiboyacense (Roa, 2005). 


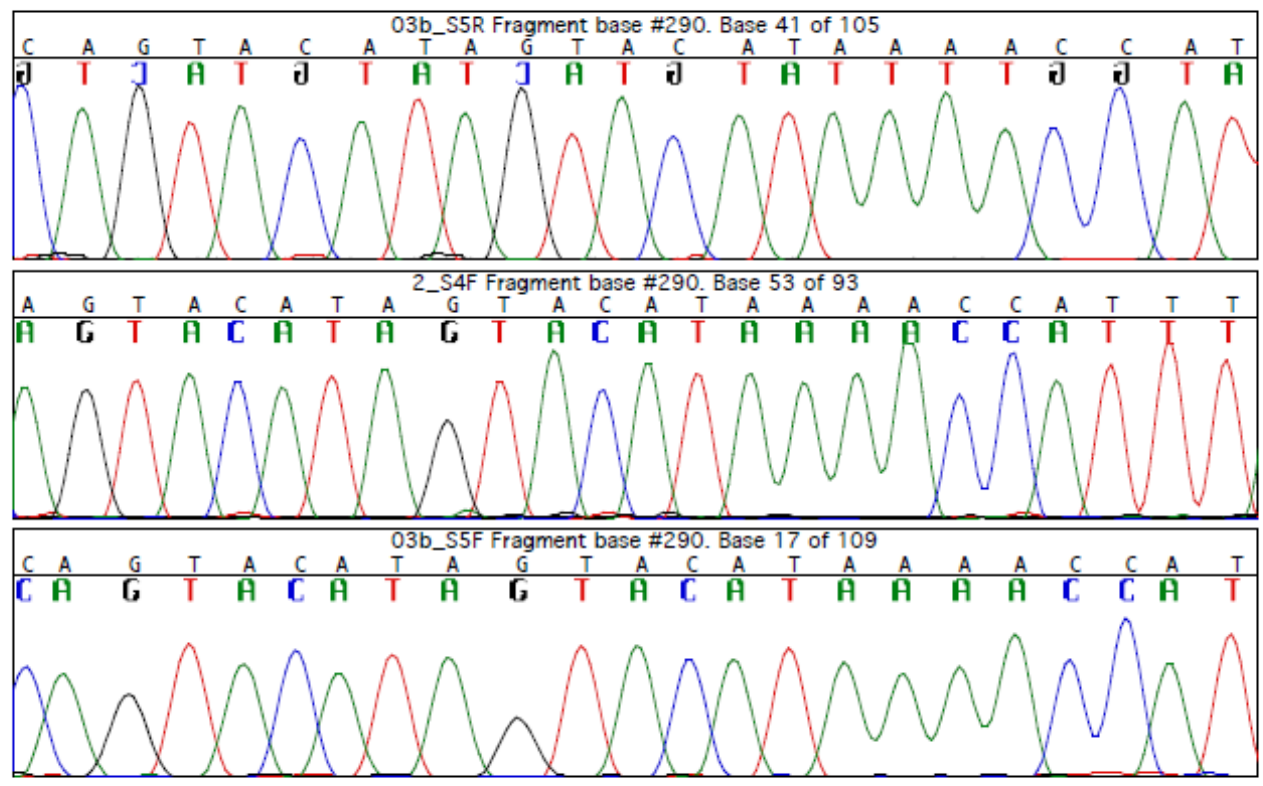

Figura 4. Electroferograma del ADNmt extraído de los restos de un individuo checua. Tomado de: Díaz-Matallana (2014)

Tabla 3. Haplogrupos (HG) y haplotipos del ADNmt en 12 restos óseos de la cultura checua.

\begin{tabular}{|c|c|c|c|}
\hline Muestra & Antigüedad* & Haplotipo & HG \\
\hline CHI-03a & ND & $16111 \mathrm{~T} \quad 16223 \mathrm{~T} \quad 16290 \mathrm{~T}$ 16319A $16362 \mathrm{C}$ & $A 2$ \\
\hline CHI-03b & ND & 16111T 16223T 16290T 16319A 16362C & $A 2$ \\
\hline CHI-11 & ND & 16111T 16223T 16290T 16319A 16362C & $A 2$ \\
\hline CHI-13 & $8.200-7.200$ a. P. & 16111T 16115T 16223T 16290T 16319A $16362 \mathrm{C}$ & $A 2$ \\
\hline CHII-03 & ND & $16111 \mathrm{~T} 16290 \mathrm{~T} 16319 \mathrm{~A} \quad 16362 \mathrm{C}$ & $A 2$ \\
\hline CHII-04 & ND & 16111T 16223T 16290T 16319A 16362C & $A 2$ \\
\hline CHII-05 & ND & 16111T 16223T 16290T 16319A 16362C & $A 2$ \\
\hline CHI-07 & $7.800-6.800$ a. P. & 16183C 16189C 16217C 16244A 16274A & $B 2$ \\
\hline CHII-06 & ND & $16183 \mathrm{C} 16189 \mathrm{C} 16217 \mathrm{C}$ & $B 2$ \\
\hline CHI-01 & $\mathrm{ND}$ & 16183C 16189C $16217 \mathrm{C}$ & $B 2$ \\
\hline CHI-08 & $7.800-6.800$ a. P. & $16223 \mathrm{~T} 16298 \mathrm{C} \quad 16325 \mathrm{C} \quad 16327 \mathrm{~T}$ & $C 1$ \\
\hline CHI-02 & ND & $16223 \mathrm{~T} 16241 \mathrm{G} 16301 \mathrm{~T} 16342 \mathrm{C} 16362 \mathrm{C}$ & $D 4 h 3 a$ \\
\hline
\end{tabular}

Tabla modificada a partir de Díaz-Matallana, et al., 2016. *Datación mediante ${ }^{14} \mathrm{C}$ convencional según Neves, et al., 2007

c) Periodo Muisca tardío. En el marco de una colaboración en curso con la Universidad de los Andes, se recuperó ADN antiguo de 18 individuos pertenecientes a la sociedad muisca del periodo tardío (1200-1600 d.C.) en Tibanica (Soacha), Bogotá, Colombia. Se amplificó la región hipervariable (HVSI) del ADNmt de segmentos de restos óseos antiguos. Las secuencias resultantes están siendo analizadas en este momento. El análisis de haplogrupos y haplotipos se complementó en esta población con la determinación del sexo de cada resto funerario, gracias a la estandarización de la amplificación de los genes SRY, Amelogenina- $X$ y Amelogenina- $Y$. Gracias a este análisis se pudo determinar, por ejemplo, que una de las muestras correspondía a una mujer según la ausencia de las bandas características del cromosoma Y (genes $S R Y$ y Amelogenina-Y). El sexo en esta muestra había sido clasificado por los antropólogos del equipo como "indeterminado" con base en las variables clásicas de la antropología física; en consecuencia, este hallazgo molecular permitió evidenciar una vez más las ventajas de la aproximación genética como complemento de la aproximación tradicional de la antropología física.

Además, se encuentra en estudio la relación de parentesco entre los individuos de esta comunidad precolombina que presentan ajuares en sus sepulturas, bajo la premisa de que 


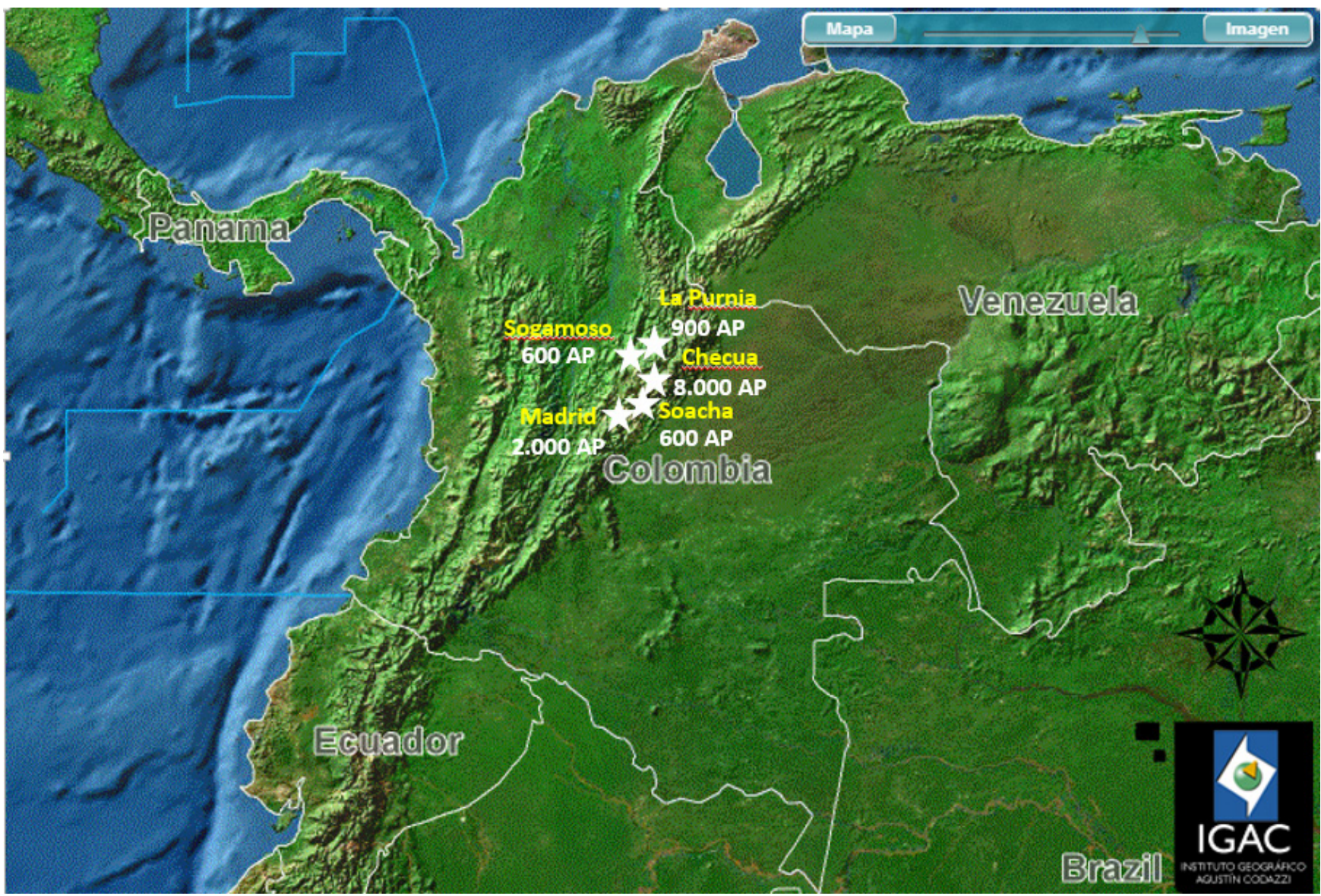

Figura 5. Hallazgos arqueológicos estudiados en el Instituto de Genética Humana. Modificado a partir de: Instituto Geográfico Agustín Codazzi (http://geoportal.igac.gov.co/ssigl2.0/visor/galeria.req?mapaId=22)

las altas jerarquías se transmitían en los muiscas de este periodo a través del linaje materno. De ser así, se deberán encontrar linajes mitocondriales semejantes o idénticos en los restos óseos de lo que los antropólogos han denominado "la élite".

d) Guanes. La datación de contexto del hallazgo correspondiente a estos restos óseos se fijó en el año $1.090 \pm 70$ d.C., es decir cerca de 400 años antes de la conquista española. En ese sentido, sería más preciso hablar de la cultura "protoguane", puesto que los guanes fueron denominados como tales por los cronistas conquistadores. Al tipificar el ADN mitocondrial de 17 individuos exhumados de un abrigo rocoso en el distrito de La Purnia, se encontró que $35 \%$ de ellos presentaba el haplo-grupo A, $41 \%$, el haplogrupo B y $24 \%$, el haplogrupo $\mathrm{D}$, con ausencia aparente del haplogrupo $\mathrm{C}$.

Un total de nueve haplotipos diferentes caracterizaron a este grupo humano, lo cual significa que estaba compuesto por un mínimo de nueve familias diferentes desde el punto de vista materno. Entre éstos, tres haplotipos no habían sido reportados en ningún individuo americano, ni moderno ni precolombino. Los dos primeros se habían reportado en individuos asiáticos, lo que respalda, una vez más, la filiación remota compartida de América y Asia, y el tercero se ha considerado como un haplotipo privado hasta que se pruebe lo contrario, es decir, exclusivo de esta población precolombina mientras no aparezca reportado en otra comunidad asiática o americana.

En conclusión, los "protoguanes" parecen haber sido una comunidad particularmente diversa desde el punto de vista molecular, con evidentes parentescos con los muiscas y sus descendientes contemporáneos, a pesar de la aparente homogeneidad craneana reportada por los antropólogos físicos como característica de esta comunidad. Con base en esta particularidad, se puede postular una población relativamente numerosa por cuanto no se halló evidencia de un entrecruzamiento intrafamiliar que condujera a la homogeneidad genética, lo cual puede ser resultado de las condiciones ambientales en la región central de los Andes orientales de Colombia, favorables a una mayor extensión territorial y una mayor densidad demográfica comparadas con otras poblaciones prehispánicas (Casas-Vargas, et al., 2011).

e) Muiscas del Templo del Sol. El análisis arqueológico y genético-poblacional en curso de restos óseos precolombinos de la sociedad muisca asociada al Templo del Sol en Sogamoso (Casas-Vargas, et al., 2017), permitirá confirmar 
o refutar la tradicional hipótesis de orígenes ancestrales diferentes para los muiscas del norte (liderados por el Zaque) y los muiscas del sur (liderados por el Zipa) en la sabana de Bogotá (Rodríguez, 2011). Asimismo, se podrán dar luces sobre la continuidad genética de los pobladores de este territorio a través de los tiempos de ocupación.

Por el momento, en el marco del trabajo colaborativo de Andrea Casas-Vargas, estudiante doctoral de nuestro equipo, con el antropólogo José Vicente Rodríguez de la Universidad Nacional de Colombia, se ha podido registrar ya la presencia de los haplogrupos A2, B2 y $\mathrm{C} 1$, hallados también en los individuos paleoamericanos de la cultura checua (DíazMatallana, et al., 2016). En 13 individuos analizados hasta el momento en los restos de la zona circundante del Templo del Sol, se encontraron tres haplogrupos diferentes, nueve correspondientes al haplogrupo A2, tres al haplogrupo B2 y uno al haplogrupo $\mathrm{C} 1$, revelando, una vez más, una alta diversidad en una muestra poblacional relativamente pequeña. A estos restos óseos se les pudo practicar, adicionalmente, un análisis de género molecular mediante la amplificación del gen de la amelogenina, cuyas características alélicas son diferentes en el cromosoma $\mathrm{Y}$ y en el cromosoma $\mathrm{X}$, lo que permitió confirmar en 12 de los 13 individuos el sexo reportado por el análisis preliminar antropológico de los restos óseos y, en un solo caso, corregir el sexo previamente determinado, por cuanto el individuo SM68 se había clasificado como femenino y presentó evidencia molecular de corresponder a un individuo masculino XY (Tabla 4) (Casas-Vargas, et al., 2017).

Según los datos provisionales producto de nuestras investigaciones moleculares cuidadosamente controladas, y que cubren un espectro relativamente amplio de tiempos y zonas de poblamiento diferentes en la región central de los Andes orientales, la filiación de los pobladores precolombinos de la cordillera oriental de Colombia analizados se mantiene en los cuatro haplogrupos característicos de todos los indígenas americanos, y presenta haplotipos privados y públicos. La coincidencia de algunos de estos haplogrupos y sub-haplogrupos en diferentes comunidades a lo largo de Norteamérica y Suramérica permite sustentar diversas hipótesis sobre la migración progresiva en sentido principal de norte a sur, la cual determinó el acceso a diferentes regiones del continente en los últimos 20.000 años.

\section{Modelos de las oleadas migratorias hacia Suramérica}

En los estudios de antropología física y molecular en poblaciones modernas y ancestrales, se han sustentado diferentes modelos de inmigración de los primeros pobladores de América. Mientras en algunos reportes se apoya una única migración (Moraga, et al., 2000; Wang, et al., 2007; Fagundes, et al., 2008), otros investigadores sugieren al menos dos (Keyeux, et al., 2002; Rothhammer \& Dillehay, 2009) o tres oleadas (Reich, et al., 2012), con uno o varios componentes sucesivos presentes en los sistemas montañosos de los Andes.
A partir de muestras indígenas del extremo sur de Suramérica, se han sugerido tres modelos de inmigración para este subcontinente (Bodner, 2012). Estos autores consideran que el más probable de los tres corresponde al de la migración costera de norte a sur, con colonización transandina del interior subcontinental, seguida por extensas migraciones transandinas con flujo génico bidireccional de este a oeste. La Patagonia habría sido poblada hace aproximadamente 15.000 años por migrantes que siguieron la ruta costera del Pacífico. Una vez llegaron a la zona de Monte Verde, no pudieron avanzar más a lo largo de la costa debido a la extensión de los glaciares que cubrían la mayor parte de la Patagonia, y entonces habrían cruzado los Andes y continuado su avance hacia el sur y hacia el interior por el costado oriental de la cordillera.

Recientemente se reportó la existencia contemporánea del linaje D4h3a5 en Patagonia y Tierra del Fuego, con lo cual se refuerza la hipótesis de la continuidad de las poblaciones patagónicas actuales con respecto a los grupos fundadores (De Saint-Pierre, 2012).

Además del hallazgo de este particular sublinaje mitocondrial de origen asiático, restringido a la región más austral del Cono Sur de Suramérica, las dataciones más antiguas asociadas a otros linajes moleculares típicamente americanos, como el D1 y el B2, permiten sustentar la hipótesis de que los primeros asentamientos de América datan de 18.000 a 20.000 años a. P. En consecuencia, los primeros pobladores del extremo sur suramericano habrían tomado de 3.000 a 5.000 años para llegar desde el estrecho de Bering hasta la Patagonia. Los resultados moleculares indican que las poblaciones nativas actuales del sur de Chile y de Argentina tuvieron un origen común, y que el proceso de colonización temprana no solo consistió de una expansión de norte a sur por la costa del Pacífico, sino también de movimientos poblacionales a través de los Andes que explicarían el poblamiento temprano y relativamente disperso del territorio colombiano. En función de los hallazgos presentados en el presente documento, se puede tomar específicamente el sub-clado D4h3a como un buen marcador de inmigración americana. La presencia de este marcador en restos óseos hallados en la sabana de Bogotá, con una antigüedad aproximada de 5.000 años a. P., provee evidencia genética de la dispersión y el arribo a este territorio de individuos paleoamericanos por la ruta de la costa Pacífica, con una sucesiva migración transandina que llevó este linaje al menos hasta el altiplano cundiboyacense.

Un reciente hallazgo molecular en el ADN del cromosoma Y de más de 1.000 indígenas nativos americanos actuales concuerda con la tesis de un poblamiento inicial de Suramérica en los tiempos inmediatamente posteriores a la glaciación de Würm/Wisconsin, seguido de largos períodos de aislamiento en pequeños grupos tribales $\mathrm{y}$, eventualmente, de nuevas oleadas de pobladores provenientes de Asia (Roewer, et al., 2013). Además, en este mismo trabajo se pudo identificar un nodo fundador de linajes paternos, 
Tabla 4. Análisis de sexo de los 13 individuos asociados al Templo del Sol.

\begin{tabular}{|c|c|c|c|c|c|c|c|c|c|}
\hline \multirow{2}{*}{$\begin{array}{l}\text { Individuo } \\
\text { SM27 }\end{array}$} & \multicolumn{2}{|c|}{ Cementerio arqueológico } & \multicolumn{2}{|c|}{ Edad antropológica } & \multicolumn{2}{|c|}{ Sexo antropológico } & Biotipo & \multicolumn{2}{|c|}{ Cronología } \\
\hline & \multicolumn{2}{|c|}{ MAS } & \multicolumn{2}{|c|}{ Adulto (40-50 años) } & \multicolumn{2}{|c|}{ Femenino } & Braquicéfalo & \multicolumn{2}{|c|}{ siglos IX-XVI d.C. } \\
\hline SM30 & \multicolumn{2}{|c|}{ MAS } & \multicolumn{2}{|c|}{ Adulto (40-50 años) } & \multicolumn{2}{|c|}{ Femenino } & Braquicéfalo & \multicolumn{2}{|c|}{ siglos IX-XVI d.C. } \\
\hline SM31 & \multicolumn{2}{|c|}{ MAS } & \multicolumn{2}{|c|}{ Adulto (40-50 años) } & \multicolumn{2}{|c|}{ Femenino } & Braquicéfalo & \multicolumn{2}{|c|}{ siglos IX-XVI d.C. } \\
\hline SM39 & \multicolumn{2}{|c|}{ MAS } & \multicolumn{2}{|c|}{ Adulto (30-40 años) } & \multicolumn{2}{|c|}{ Femenino } & Braquicéfalo & \multicolumn{2}{|c|}{ siglos IX-XVI d.C. } \\
\hline SM43 & \multicolumn{2}{|c|}{ MAS } & \multicolumn{2}{|c|}{ Desconocido } & \multicolumn{2}{|c|}{ Femenino } & Braquicéfalo & \multicolumn{2}{|c|}{ siglos IX-XVI d.C. } \\
\hline SM44 & & AS & Adu & 40-50 años) & & enino & Braquicéfalo & sigl & -XVI d.C. \\
\hline SM47 & & AS & Adu & 40-50 años) & & enino & Braquicéfalo & sigl & -XVI d.C. \\
\hline SM50 & & AS & Adu & 40-50 años) & & enino & Braquicéfalo & sigl & -XVI d.C. \\
\hline SM61 & & AS & Des & cido & & enino & Braquicéfalo & sigl & -XVI d.C. \\
\hline SM67 & & AS & Adu & 30-40 años) & & enino & Braquicéfalo & sigl & -XVI d.C. \\
\hline SM68 & & $\mathrm{AS}$ & Adu & 50-60 años) & & enino & Braquicéfalo & sigl & -XVI d.C. \\
\hline SM104 & & AS & Des & cido & & culino & Braquicéfalo & sigl & -XVI d.C. \\
\hline SM109 & & AS & Adu & 40-50 años) & & culino & Braquicéfalo & sigl & -XVI d.C. \\
\hline Individuo & SM27 & SM31 & SM39 & SM43 & SM44 & SM47 & SM68 & SM104 & SM109 \\
\hline D3S1358 & $16 / 18$ & $14 / 15$ & $15 / 18$ & $15 / 16$ & 16 & 16 & 15 & 15 & $15 / 16$ \\
\hline VWA & $14 / 16$ & $16 / 17$ & $-{ }^{\mathrm{a}}$ & $-{ }^{\mathrm{a}}$ & $16 / 19$ & 15 & 16 & ${ }_{-}^{\mathrm{a}}$ & 16 \\
\hline D16S539 & $10 / 12$ & 12 & ${ }^{\mathrm{a}}$ & 5 & $11 / 12$ & ${ }^{\mathrm{a}}$ & ${ }_{-}^{a}$ & _a & $11 / 12$ \\
\hline D2S1338 & 17 & $22 / 23$ & ${ }_{-}^{\mathrm{a}}$ & ${ }^{\mathrm{a}}$ & 22 & ${ }^{\mathrm{a}}$ & ${ }^{\mathrm{a}}$ & ${ }_{-}^{\mathrm{a}}$ & 18 \\
\hline Amelogenina & $X$ & X & $\mathrm{X}$ & $\mathrm{X}$ & $\mathrm{X}$ & $\mathrm{X}$ & $\mathrm{X} / \mathrm{Y}$ & $\mathrm{X} / \mathrm{Y}$ & $\mathrm{X} / \mathrm{Y}$ \\
\hline D8S1179 & 14 & $12 / 13$ & 13 & ${ }^{\mathrm{a}}$ & $11 / 14$ & 13 & $13 / 14$ & $12 / 13$ & 13 \\
\hline SE33 & $19 / 28.2$ & $19 / 29.2$ & ${ }_{-}^{\mathrm{a}}$ & $\mathrm{a}^{\mathrm{a}}$ & a & a & ${ }^{\mathrm{a}}$ & - a & $14 / 17$ \\
\hline D19S433 & $13 / 15$ & $13.2 / 14$ & ${ }^{\mathrm{a}}$ & ${ }^{\mathrm{a}}$ & $13 / 15$ & $14 / 14.2$ & $13.2 / 14$ & $14 / 15$ & $13 / 15$ \\
\hline TH01 & $7 / 9$ & 7 & ${ }^{\mathrm{a}}$ & $\mathrm{a}^{\mathrm{a}}$ & $6 / 7$ & $7 / 9$ & 7 & - a & $6 / 7$ \\
\hline FGA & $22 / 27$ & $19 / 25$ & ${ }^{\mathrm{a}}$ & ${ }_{-}^{\mathrm{a}}$ & $24 / 26$ & $-^{\mathrm{a}}$ & ${ }_{-}^{\mathrm{a}}$ & ${ }_{-}^{\mathrm{a}}$ & $23 / 24$ \\
\hline D21S11 & $31 / 31.2$ & $30.2 / 32.2$ & $-^{\mathrm{a}}$ & a & $28 / 33.2$ & 30 & 30 & $-\mathrm{a}$ & $28 / 32.2$ \\
\hline D18S51 & _a & $13 / 14$ & $\mathrm{a}^{\mathrm{a}}$ & _a & $\_{ }^{\mathrm{a}}$ & $\_{ }^{\mathrm{a}}$ & a & _a & $14 / 16$ \\
\hline
\end{tabular}

MAS: Museo Arqueológico de Sogamoso;_a: ausencia preliminar de resultado en la amplificación genética correspondiente.

el haplogrupo C-M217 (C3*), el cual se halla restringido al territorio de Ecuador en el noroeste suramericano. Este mismo haplogrupo se encuentra con mucha frecuencia en el centro, este y noreste asiáticos, pero hoy está virtualmente ausente en Norteamérica y Centroamérica, con la excepción de Alaska. Esta distribución geográfica, unida a los estudios de coalescencia molecular que permiten determinar el momento cronológico del ancestro común más reciente en linajes semejantes, sustentan la hipótesis de la llegada de este haplogrupo al Ecuador por la vía costera o por la vía transpacífica cerca de 6.000 años a. P.

Los diversos estudios en un número importante de restos óseos disponibles hoy en museos y otras colecciones, además de los estudios a partir de muestras de indígenas contemporáneos en el siglo XXI, permitirán precisar las rutas de poblamiento americano y llegar a conclusiones sobre el grado de filiación de las comunidades humanas que han habitado el territorio de Colombia a lo largo de su historia.

\section{La evidencia genética de los primeros pobladores desde el punto de vista médico}

Una vez definidos los referentes moleculares en el ADNmt y el ADNcrY, que han arrojado luz sobre las rutas preliminares y la filiación de los primeros pobladores, se considerarán en esta sección algunos aspectos relacionados con la evidencia médica que permite un diagnóstico del estado de salud de las poblaciones precolombinas. Este diagnóstico puede basarse tanto en las observaciones contenidas en los textos de los cronistas de Indias, como en el estudio de los restos orgánicos de los hallazgos arqueológicos y las representaciones culturales de los grupos indígenas ancestrales americanos.

Una de las principales evidencias genéticas de los primeros pobladores americanos proviene del análisis de la cerámica prehispánica, particularmente aquella elaborada por el grupo humano asentado en la frontera con el actual Ecuador conocido como Tumaco-La Tolita. Este grupo, del que se perdió la traza hace más de 2.000 años, dejó cientos de 
figuras de cerámica que registran su vida cotidiana, su entorno y sus mitos. Entre ellas se encuentran varias que representan con la más exquisita finura una serie de enfermedades y permiten vislumbrar características de su estructura genética y testimoniar casos de síndrome de Down, acondroplasia, mucopolisacaridosis, tumores faciales y enfermedades infecciosas (Gómez, Briceño \& Bernal, 2007).

Como en el caso de los marcadores del ADN, las proyecciones ancestrales son posibles mediante el estudio de las enfermedades presentes hoy en las comunidades indígenas contemporáneas y de aquellas detectadas directamente en los restos óseos y dentales de las poblaciones precolombinas o, eventualmente, en restos momificados, como lo hicieron los académicos Gonzalo Correal (Correal \& Flórez, 1992; Burgos, Correal \& Arregocés, 1994; Correal, 2004) y José Vicente Rodríguez (Rodríguez, 1992, 1999, 2006) en varios estudios pioneros en Colombia, y como lo viene haciendo, por ejemplo, el antropólogo Carl Henrik Langebaek (Langebaek, 1988; Langebaek, et $\boldsymbol{a l} ., 2011)$. En este punto debe señalarse que se dispone de una reciente revisión de la paleopatología en América Latina publicada en 2007 por el Convenio Andrés Bello y la Asociación Latinoamericana de Academias Nacionales de Medicina (ALANAM) (Sotomayor \& Cuéllar, 2007).

\section{Estudios moleculares en individuos con evidencia de trepanación craneana}

Uno de los hallazgos arqueológicos que se han asociado a la medicina precolombina es la existencia de restos óseos con trepanaciones craneanas. Un número significativo de estas trepanaciones permite suponer la supervivencia del individuo correspondiente, en la medida en que se ha hallado evidencia de regeneración tisular en los bordes del orificio trepanado. Los cráneos de los individuos sometidos a tales cirugías se encuentran en diferentes culturas, y se han descrito también en Colombia (Gómez-González \& Correal, 1973; Correal, 2004). A partir de muestras aisladas de estos hallazgos particulares, nuestro grupo de investigación ha extraído, amplificado y secuenciado el ADN mitocondrial de tres individuos prehispánicos hallados en los años 70 del siglo XX por Gonzalo Correal Urrego y Jaime Gómez González en territorio muisca en Colombia (Díaz-Matallana, et al., 2012a), y de un individuo hallado en los años 60 del siglo pasado por Jorge Reynolds Pombo en territorio de la cultura precolombina de los paraca en el Perú (Díaz-Matallana, et al., 2012b).

Uno de los cráneos hallados en territorio muisca fue datado en $350 \pm 50$ años d.C. (cerca de 1.700 años a. P.) (Gómez-González \& Correal, 1973). Al tipificar su ADN, se encontró que dos de los tres cráneos muiscas (provenientes de Belén, Boyacá, y Nemocón, Cundinamarca) pertenecían al haplogrupo A2. El tercer cráneo, proveniente de una excavación en Sopó, Cundinamarca, pertenecía al haplogrupo B2 y presentaba el mismo cambio nucleotídico en la posición 16221 que el hallado en los restos óseos de la cultura Herrera del periodo Formativo temprano (Silva, et al., 2007), pero también un nucleótido diferente en la posición 16217, lo cual lo relaciona con este individuo precursor en el altiplano de manera un poco más distante (Díaz-Matallana, et al., 2012a).

\section{Conclusión}

En síntesis, las evidencias genéticas clínicas y moleculares de los primeros pobladores corresponden a áreas de estudio cada vez más precisas. Con base en ellas puede entenderse que los primeros pobladores americanos eran grupos humanos migrantes que venían de lejos, desde el centro de África, y que, una vez salidos de ese continente les tomó alrededor de 40.000 años llegar hasta el estrecho de Bering y, a partir de su ingreso en América hace cerca de 20.000 años, 4.000 años más para llegar hasta la Patagonia. Una vez instalados en cada uno de los ecosistemas seleccionados en el continente americano, estos grupos humanos se reprodujeron $\mathrm{y}$ diversificaron con base en los factores ambientales y genéticos determinantes que consolidaron los grupos étnicos encontrados por los conquistadores europeos en los últimos años del siglo XV, así como otros eventuales viajeros trasatlánticos o transpacíficos que dejaron, infortunadamente, una muy precaria documentación de sus viajes.

Los hallazgos y reportes de la genética molecular, así como los reportes basados en aproximaciones complementarias, que permitan entender la estructura biológica de estos pobladores, serán esenciales para tipificar convenientemente las primeras sociedades que poblaron el territorio colombiano como lo han sido para tipificar y definir identidades en las generaciones del presente.

\section{Agradecimientos}

El presente texto es resultado de conversaciones sostenidas y de trabajos colectivos liderados conjuntamente con Ignacio Briceño Balcázar y Jaime Bernal Villegas en el Instituto de Genética Humana. Producto de estas interacciones fue la ponencia inaugural conjunta presentada en noviembre de 2014 en el seminario "La economía prehispánica en Colombia” organizado por el Banco de la República y la Universidad de los Andes en las instalaciones de la Biblioteca Luis Ángel Arango de Bogotá. Posteriormente, el autor presentó versiones individuales y actualizadas de esta reflexión en la Cátedra Europa realizada en la Universidad del Norte en Barranquilla en marzo de 2015 y en el XIII Congreso de Investigación de la Pontificia Universidad Javeriana, en septiembre de 2015. El autor agradece a los estudiantes de pregrado y posgrado que han participado en la línea de investigación "Diversidad humana en Colombia" del Instituto de Genética Humana en la Facultad de Medicina de la Pontificia Universidad Javeriana, al grupo de Antropología Molecular dirigido por Deborah A. Bolnick en la Universidad de Texas en Austin, al grupo de Arqueología y Antropología dirigido por Carl H. Langebaek y al grupo del Laboratorio de Genética 
Humana dirigido por Helena Groot en la Universidad de los Andes, así como al grupo del Laboratorio de Antropología Física de la Universidad Nacional de Colombia liderado por José Vicente Rodríguez. Mención especial merecen las estudiantes doctorales Andrea Casas-Vargas, Marcela DíazMatallana y María Claudia Noguera-Santamaría, quienes han logrado obtener resultados moleculares confiables y bien controlados, de acuerdo con estrictas condiciones de experimentación en los laboratorios de ADN antiguo de la Pontificia Universidad Javeriana, de la Universidad de los Andes y de la Universidad Nacional. Los análisis moleculares de restos óseos y dentales precolombinos han sido formalmente autorizados por el Instituto Colombiano de Antropología e Historia (ICANH), a cuyo equipo presentamos nuestro reconocimiento institucional por su amabilidad y diligencia. Finalmente, debo agradecer personalmente al profesor Gonzalo Correal por las muy generosas e interesantes conversaciones que he compartido con él en diferentes escenarios, públicos y privados, en relación con sus hallazgos precursores en este dominio de la ciencia en Colombia.

\section{Conflicto de intereses}

El autor declara que no tiene conflictos de intereses con respecto al contenido del artículo.

\section{Referencias}

Aceituno, F. J., Loaiza, N., Delgado-Burbano, M. E., Barrientos, G. (2013). The initial human settlement of Northwest South America during the Pleistocene/Holocene transition: Synthesis and perspectives. Quaternary International. 301: 23-33.

Achilli, A., Perego, U. A., Bravi, C. M., Coble, M. D., Kong, Q. P., Woodward, S. R., Salas, A., Torroni, A. \& Bandelt, H. J. (2008). The phylogeny of the four pan-American mtDNA haplogroups: Implications for evolutionary and disease studies. PLoS One. 3 (3): e1764.

Achilli, A., Perego, U. A., Lancioni, H., Olivieri, A., Gandini, F., Hooshiar Kashani, B., Battaglia, V., Grugni, V., Angerhofer, N., Rogers, M. P., Herrera, R. J., Woodward, S. R., Labuda, D., Smith, D. G., Cybulski, J. S., Semino, O., Malhi, R. S. \& Torroni, A. (2013). Reconciling migration models to the Americas with the variation of North American native mitogenomes. Proceedings of the National Academy of Sciences. 110 (35): 14308-14313.

Battaglia, V., Grugni, V., Perego, U. A., Angerhofer, N., GómezPalmieri, J. E. Woodward, S. R., Achilli, A., Myres, N., Torroni, A. \& Semino, O. (2013). The first peopling of South America: New evidence from Y-chromosome haplogroup Q. PLoS One. 8 (8): e71390.

Bisso-Machado, R., Bortolini, M. C. \& Salzano, F. M. (2012). Uniparental genetic markers in South Amerindians. Genetics and Molecular Biology. 35 (2): 365-387.

Bodner, M., Perego, U. A., Huber, G., Fendt, L., Röck, A. W., Zimmermann, B., Olivieri, A., Gómez-Carballa, A., Lancioni, H., Angerhofer, N., Bobillo, M. C., Corach, D., Woodward, S. R., Salas, A., Achilli, A., Torroni, A., Bandelt, H. J., Parson, W. (2012). Rapid coastal spread of first Americans: Novel insights from South America's Southern Cone mitochondrial genomes. Genome Research. 22: $811-820$

Bolnick, D. A. Díaz-Matallana, M, Mata-Miguez, J., Pintar, E. \& Martínez, J. G. (2014). Ancient DNA from Early to Mid-Holocene Burials in Northwestern Argentina: Implications for Understanding the Colonization and Early Population History of South America. American Journal of Physical Anthropology. 153 (S58): 81-81.

Botiva Contreras, A., Groot de Mahecha, A. M., Herrera, L. \& Mora, S. (1989). Colombia prehispánica. Regiones arqueológicas. Bogotá: Colcultura - Instituto Colombiano de Antropología.

Bryc, K., Auton, A., Nelson, M. R., Oksenberg, J. R., Hauser, S. L., Williams, S., Froment, A., Bodo, J. M., Wambebe, C., Tishkoff, S. A., Bustamante, C. D. (2010). Genomewide patterns of population structure and admixture among Hispanic/Latino populations. Proceedings of the National Academy of Sciences USA. 107 (2): 8954-8961.

Burgos, J. D., Correal-Urrego, G. \& Arregocés, C. (1994). Treponematosis en restos óseos precerámicos de Colombia. Revista de la Academia Colombiana de Ciencias Exactas, Físicas y Naturales. 19 (73): 237-241.

Carelli, V. (2015). Keeping in shape the dogma of mitochondrial DNA maternal Inheritance. PLoS Genetics. 11 (5): e1005179.

Casas-Vargas, A., Gómez, A., Briceño, I., Díaz-Matallana, M., Bernal, J. E. \& Rodríguez, J. V. (2011). High genetic diversity on a sample of pre-Columbian bone remains from Guane territories in Northwestern Colombia. American Journal of Physical Anthropology. 146: 637-649.

Casas-Vargas, A., Romero, L. M., Usaquén, W., Zea, S., Silva, M., Briceño, I., Gómez, A. \& Rodríguez, J. V. (2017). Diversidad del ADN mitocondrial en restos óseos prehispánicos asociados al Templo del Sol en los Andes orientales colombianos. Biomédica. 37 (4): publicación anticipada, 2017.

Castaño Uribe, C. \& Van der Hammen, T. (1986). Parque Nacional Natural Chiribiquete. La peregrinación de los jaguares. Bogotá: Ministerio del Medio Ambiente.

Correal Urrego, G. (1971). Hacia los orígenes y antigüedad del hombre en Colombia. Bogotá: Contraloría General de la República.

Correal Urrego, G. (1973). Los hallazgos arqueológicos paleoindígenas y la antigüedad del hombre en Colombia. Bogotá: ICAN.

Correal Urrego, G. (1979). Investigaciones arqueológicas en abrigos rocosos de Nemocón y Sueva. Bogotá: Fundación de Investigaciones Arqueológicas Nacionales, Banco de la República.

Correal Urrego, G. (2004). Enfermedades en la población guane: fenotipo y craneoplastias. Boletín de Historia y Antigüedades. 824: 55-71.

Correal Urrego, G. \& Van der Hammen, T. (1977). Investigaciones arqueológicas en los abrigos rocosos del Tequendama. Bogotá: Banco Popular.

Correal, G. \& Flórez, I. (1992). Estudio de momias guanes en la Mesa de los Santos. Revista de la Academia Colombiana de Ciencias Exactas, Físicas y Naturales. 18 (70): 283-289.

Coutinho, A., Valverde, G., Fehren-Schmitz, L., Cooper, A., Barreto Romero, M. I., Flores Espinoza, I., Llamas, B. \& Haak, W. (2014). AmericaPlex26: A SNaPshot multiplex system for genotyping the main human mitochondrial founder lineages of the Americas. PLoS One. 9 (3): e93292. 
Cui, Y., Lindo, J., Hughes, C. E., Johnson, J. W., Hernández, A. G., Kemp, B. M., Ma, J., Cunningham, R., Petzelt, B., Mitchell, J., Archer, D., Cybulski, J. S. \& Malhi, R. S. (2013). Ancient DNA Analysis of Mid-Holocene Individuals from the Northwest Coast of North America Reveals Different Evolutionary Paths for Mitogenomes. PLoS One. 8 (7): e66948.

De Saint-Pierre, M., Bravi, C. M., Motti, J. M., Fuku, N., Tanaka, M., Llop, E., Bonatto, S. L. \& Moraga, M. (2012). An Alternative Model for the Early Peopling of Southern South America Revealed by Analyses of Three Mitochondrial DNA Haplogroups. PLoS One. 7 (9): e43486.

Delgado, M. E. (2012a). Diversificación morfológica y poblamiento temprano del noroccidente de Suramérica: un estudio de la variación craneofacial. Revista Colombiana de Antropología. 48 (1): 189-232.

Delgado, M. E. (2012b). Mid and Late Holocene population changes at the Sabana de Bogotá (Northern South America) inferred from skeletal morphology and radiocarbon chronology. Quaternary International. 256: 2-11.

Delgado, M. E. (2017). Sinopsis de la arqueología y la bioantropología del poblamiento temprano del noroccidente de Sudamérica. Revista Colombiana de Antropología. 53 (1): 213-239.

Díaz-Matallana, M. (2014). Caracterización genética de la cultura Checua del período Paleoindio proveniente de NemocónCundinamarca, Colombia. Implicaciones para el Poblamiento Temprano de Suramérica. Tesis Doctoral. Bogotá: Facultad de Ciencias - Pontificia Universidad Javeriana.

Díaz-Matallana, M., Briceño-Balcázar, I., Reynolds-Pombo, J. \& Gómez-Gutiérrez, A. (2012b). Tipificación de ADN mitocondrial precolombino a partir de restos dentales de un individuo con cráneo trepanado perteneciente a la cultura de los paracas (Perú). Medicina. 34 (1): 17-24.

Díaz-Matallana, M., Gómez, A., Briceño, I. \& Correal, G. (2012a). Análisis de ADN ancestral en restos óseos de tres individuos trepanados encontrados en territorio muisca. Simposio de Antropología Genética - VI Congreso Internacional de Genética Humana, Santa Marta, Colombia.

Díaz-Matallana, M., Gómez, I., Briceño, I., Bernal, J. E. \& Rodríguez, J. V. (2016). Genetic analysis of PaleoColombians from Nemocón, Cundinamarca, provides insights on the early peopling of northwestern South America. Revista de la Academia Colombiana de Ciencias Exactas, Físicas y Naturales. 40 (156): 461-483.

Dulik, M. C. Zhadanov, S. I., Osipova, L. P., Askapuli, A., Gau, L., Gokcumen, O., Rubinstein, S., Schurr, T. G. (2012). Mitochondrial DNA and Y Chromosome variation provides evidence for a recent common ancestry between native Americans and indigenous Altaians. American Journal of Human Genetics. 90: 229-246.

Fagundes, N. J. R., Kanitz, R., Eckert, R., Valls, A. C., Bogo, M. R., Salzano, F. M., Smith, D. G., Silva, W. A. Jr, Zago, M. A., Ribeiro-dos-Santos, A. K., Santos, S. E., Petzl-Erler, M. L. \& Bonatto, S. L. (2008). Mitochondrial Population Genomics Supports a Single Pre-Clovis Origin with a Coastal Route for the Peopling of the Americas. American Journal of Human Genetics. 82: 583-592.

Fehren-Schmitz, L., Reindel, M., Cagigao, E. T., Hummel, S., Herrmann, B. (2010). Pre-Columbian population dynamics in coastal Southern Peru: A diachronic investigation of
mtDNA. Patterns in the Palpa region by ancient DNA analysis. American Journal of Physical Anthropology. 141: 208-221.

García-Bour, J., Pérez-Pérez, A., Alvarez, S., Fernández, E., López-Parra, A. M., Arroyo-Pardo, E. \& Turbón, D. (2004). Early population differentiation in extinct abori-gines from Tierra del Fuego-Patagonia: Ancient mtDNA sequences and Y-chromosome STR characterization. American Journal of Physical Anthropology. 123: 361-370.

Goebel, T., Waters, M. R. \& O'Rourke, D. H. (2008). The late Pleistocene dispersal of modern humans in the Americas. Science. 319 (5869): 1497-1502.

Gómez-Gutiérrez, A., Briceño-Balcázar I., Bernal-Villegas J. E. (2007). Hereditas, diversitas et variatio. Aproximación a la historia de la genética humana en Colombia. Bogotá: Pontificia Universidad Javeriana - Academia Nacional de Medicina.

Gómez-González, J. \& Correal-Urrego, G. (1973). Evidencias de cirugía craneana prehistórica en Colombia. Revista Colombiana de Antropología. 16: 492-505.

Greenberg, J., Turner II, C. G. \& Zegura, S. L. (1986). The settlement of the Americas: A comparison of the linguistic, dental and genetic evidence. Current Anthropology. 27: 477-497.

Groot, A. M. (1992). Checua: una secuencia cultural entre 8.500 y 3.000 años antes del presente. Bogotá: Fundación de Investigaciones Arqueológicas Nacionales.

Jara, N. P., Díaz M., Villegas, V., López de Mesa, C., Torres, D., Bernal, J., Gómez, A. \& Briceño, I. (2010). Application of authenticity criteria in mitocondrial studies on archaic bone remains from a prehispanic muisca population. Colombia Médica. 41 (4): 306-314.

Kemp, B. M., Malhi, R. S., McDonough, J., Bolnick, D. A., Eshleman, J. A., Rickards, O., Martínez-Labarga, C., Johnson, J. R., Lorenz, J. G., Dixon, E. J., Fifield, T. E., Heaton, T. H., Worl, R. \& Smith, D. G. (2007). Genetic Analysis of Early Holocene Skeletal Remains From Alaska and its Implications for the Settlement of the Americas. American Journal of Physical Anthropology. 132: 605-621.

Keyeux, G., Rodas, C., Gélvez, N. \& Carter, D. (2002). Possible migration routes into South America deduced from mitochondrial DNA studies in Colombian Amerindian populations. Human Biology. 74 (2): 211-233.

Keyeux, G. \& Usaquén, W. (2006). Rutas migratorias hacia Suramérica y el poblamiento de las cuencas de los ríos Amazonas y Orinoco deducidas a partir de estudios genéticos moleculares. En: Morcote, G., Mora, S., Franky, C. (editores.). Pueblos y paisajes antiguos de la selva amazónica. Bogotá: Universidad Nacional de Colombia, p. 49-62.

Langebaek, C. H. (1988). Patologías en la población muisca y la hipótesis de la economía autosuficiente. Revista de Antropología y Arqueología. 6 (1): 143-157.

Langebaek, C. H. (1992). Noticias de caciques muy mayores. Origen y desarrollo de sociedades complejas en el Nororiente de Colombia y Norte de Venezuela. Bogotá: Ediciones Uniandes.

Langebaek, C. H., Bernal. M., Aristizábal, L., Corcione, M. A., Rojas, C. \& Santa, T. (2011). Condiciones de vida y jerarquías sociales en el Norte de Suramérica: el caso de la población muisca en Tibanica, Soacha. Indiana. 28: 15-34. 
López-Castaño, C. E. \& Cano-Echeverri, M. C. (2011). En torno a los primeros poblamientos en el Noroccidente de Sudamérica: acercamientos desde el valle interandino del Magdalena, Colombia. Boletín de Arqueología PUCP. 15: 43-79.

Melton, P. E., Briceño, I., Gómez, A., Devor, E. J., Bernal, J. E. \& Crawford, M. H. (2007). Biological relationship between Central and South American Chibchan speaking populations: Evidence from mtDNA. American Journal of Physical Anthropology. 133: 753-770.

Mesa, N. R., Mondragón, M. C., Soto, I. D., Parra, M. V., Duque, C., Ortiz-Barrientos, D., García, L. F., Vélez, I. D., Bravo, M. L., Múnera, J. G., Bedoya, G., Bortolini, M. C. \& Ruiz-Linares, A. (2000). Autosomal, mtDNA, and Y-chromosome diversity in Amerinds: Pre- and post-Columbian patterns of gene flow in South America. American Journal of Human Genetics. 67: 1277-1286.

Moraga, M. L., Rocco, P., Miquel, J. F., Nervi, F., Llop, E., Chakraborty, R., Rothhammer, F. \& Carvallo, P. (2000). Mitochondrial DNA polymorphisms in Chilean aboriginal populations: Implications for the peopling of the southern cone of the continent. American Journal of Physical Anthropology. 113 (1): 19-29.

Neves, W. A., Hubbe, M. \& Correal, G. (2007). Human skeletal remains from Sabana de Bogotá, Colombia: A case of paleoamerican morphology late survival in South America? American Journal of Physical Anthropology. 133: 10801098.

Noguera-Santamaría, M. C., Anderson, C. E., Uricoechea, D., Durán, C., Briceño-Balcázar, I., Bernal-Villegas, J. (2015). Mitochondrial DNA analysis suggests a Chibchan migration into Colombia. Universitas Scientiarum. 20 (2): 261-278.

Pääbo, S., Poinar, H., Serre, S., Jaenicke-Després, J. H., Rohland, N., Kuch, M., Krause, J., Vigilant, L. \& Hofreiter, M. (2004). Genetic analyses from ancient DNA. Annual Review of Genetics. 38: 645-679.

Peña, S. D., Santos, F. R., Bianchi, N. O., Bravi, C. M., Carnese, F. R., Rothhammer, F., Gerelsaikhan, T., Munkhtuja, B., Oyunsuren, T. (1995). A major founder Y-chromosome haplotype in Amerindians. Nature Genetics. 11: 15-16.

Perego, U. A., Achilli, A., Angerhofer, N., Accetturo, M., Pala, M., Olivieri, A., Hooshiar Kashani, B., Ritchie, K. H., Scozzari, R., Kong, Q. P., Myres, N. M., Salas, A., Semino, O., Bandelt, H. J., Woodward, S. R., Torroni, A. (2009). Distinctive Paleo-Indian migration routes from Beringia marked by two rare mtDNA Haplogroups. Current Biology. 19 (1): 1-8.

Perego, U. A., Angerhofer, N., Pala, M., Olivieri, A., Lancioni, H., Hooshiar Kashani, B., Carossa, V., Ekins, J. E., Gómez-Carballa, A., Huber, G., Zimmermann, B., Corach, D., Babudri, N., Panara, F., Myres, N. M., Parson, W., Semino, O., Salas, A., Woodward, S. R., Achilli, A., Torroni, A. (2010). The initial peopling of the Americas: A growing number of founding mitocondrial genomes from Beringia. Genome Research. 20: 1174-1179.

PhyloTree mt. en: www.phylotree.org

Rasmussen, M., Anzick, S. L., Waters, M. R., Skoglund, P., DeGiorgio, M., Stafford, T. W. Jr, Rasmussen, S., Moltke, I., Albrechtsen, A., Doyle, S. M., Poznik, G.
D., Gudmundsdottir, V., Yadav, R., Malaspinas, A. S., White, S. S. 5th, Allentoft, M. E., Cornejo, O. E., Tambets, K., Eriksson, A., Heintzman, P. D., Karmin, M., Korneliussen, T. S., Meltzer, D. J., Pierre, T. L., Stenderup, J., Saag, L., Warmuth, V. M., Lopes, M. C., Malhi, R. S., Brunak, S., Sicheritz-Ponten, T., Barnes, I., Collins, M., Orlando, L., Balloux, F., Manica, A., Gupta, R., Metspalu, M., Bustamante, C. D., Jakobsson, M., Nielsen, R., Willerslev, E. (2014). The genome of a late Pleistocene human from a Clovis burial site in Western Montana. Nature. 506: 225-229.

Reich, D., Patterson, N., Campbell, D., Tandon, A., Mazieres, S., Ray, N., Parra, M. V., Rojas, W., Duque, C., Mesa, N., García, L. F., Triana, O., Blair, S., Maestre, A., Dib, J. C., Bravi, C. M., Bailliet, G., Corach, D., Hünemeier, T., Bortolini, M. C., Salzano, F. M., Petzl-Erler, M. L., Acuña-Alonzo, V., Aguilar-Salinas, C., CanizalesQuinteros, S., Tusié-Luna, T., Riba, L., Rodríguez-Cruz, M., López-Alarcón, M., Coral-Vázquez, R., CantoCetina, T., Silva-Zolezzi, I., Fernández-López, J. C., Contreras, A.V., Jiménez-Sánchez, G., Gómez-Vázquez, M. J., Molina, J., Carracedo, A., Salas, A., Gallo, C., Poletti, G., Witonsky, D. B., Alkorta-Aranburu, G., Sukernik, R. I., Osipova, L., Fedorova, S. A., Vásquez, R., Villena, M., Moreau, C., Barrantes, R., Pauls, D., Excoffier, L., Bedoya, G., Rothhammer, F., Dugoujon, J. M., Larrouy, G., Klitz, W., Labuda, D., Kidd, J., Kidd, K., Di Rienzo, A., Freimer, N. B., Price, A. L., Ruiz-Linares, A. (2012). Reconstructing Native American population history. Nature. 488: 370-374.

Reidla, M., Kivisild, T., Metspalu, E., Kaldma, K., Tambets, K., Tolk, H. V., Parik, J., Loogväli, E. L., Derenko, M., Malyarchuk, B., Bermisheva, M., Zhadanov, S., Pennarun, E., Gubina, M., Golubenko, M., Damba, L., Fedorova, S., Gusar, V., Grechanina, E., Mikerezi, I., Moisan, J. P., Chaventré, A., Khusnutdinova, E., Osipova, L., Stepanov, V., Voevoda, M., Achilli, A., Rengo, C., Rickards, O., De Stefano, G. F., Papiha, S., Beckman, L., Janicijevic, B., Rudan, P., Anagnou, N., Michalodimitrakis, E., Koziel, S., Usanga, E., Geberhiwot, T., Herrnstadt, C., Howell, N., Torroni, A., Villems, R. (2003). Origin and diffusion of mtDNA Haplogroup X. American Journal of Human Genetics. 73 (5): 1178-1190.

Roa, M. (2005). Polimorfismos de la región control del ADN mitocondrial humano en una muestra de población mestiza del altiplano cundiboyacense colombiano. (Tesis de Maestría). Universidad Nacional de Colombia. Bogotá, Colombia.

Rodríguez, J. V. (1992). Características físicas de la población prehispánica de la cordillera oriental. Implicaciones etnogenéticas. Maguaré. 8: 7-45.

Rodríguez, J. V. (1999). Los Chibchas: pobladores antiguos de los andes orientales. Adaptaciones bioculturales. Bogotá: Fundación de Investigaciones Arqueológicas Nacionales, Banco de la República.

Rodríguez, J. V. (2006). Las enfermedades en las condiciones de vida prehispánica de Colombia. Bogotá: Universidad Nacional de Colombia, 2006.

Rodríguez, J. V. (2007). La diversidad poblacional de Colombia en el tiempo y el espacio: estudio craneométrico. Revista de la Academia Colombiana de Ciencias Exactas, Físicas y Naturales. 31 (120): 321-346. 
Rodríguez-Cuenca, J. V. (2011). Los Chibchas: hijos del sol, la luna y los Andes. Orígenes de su diversidad. Bogotá: Universidad Nacional de Colombia.

Rodríguez, J. V. \& Vargas, C. (2015). Variación métrica y morfológica de la población prehispánica de Colombia. Implicaciones para la problemática del poblamiento temprano de América. Revista Colombiana de Antropología. 51 (2): 65-87.

Roewer, L., Nothnagel, M., Gusmão, L., Gomes, V., González, M., Corach, D., Sala, A., Alechine, E., Palha, T., Santos, N., Ribeiro-Dos-Santos, A., Geppert, M., Willuweit, S., Nagy, M., Zweynert, S., Baeta, M., Núñez, C., Martínez-Jarreta, B., González-Andrade, F., Fagundes de Carvalho, E., Da Silva, D. A., Builes, J. J., Turbón, D., López Parra, A. M., Arroyo-Pardo, E., Toscanini, U., Borjas, L., Barletta, C., Ewart, E., Santos, S., Krawczak, M. (2013). Continent-wide decoupling of Y-chromosomal genetic variation from language and geography in native South Americans. PLoS Genetics. 9 (4): e10003460.

Rothhammer, F. \& Dillehay, T. D. (2009). The Late Pleistocene colonization of South America: An interdisciplinary perspective. Annals of Human Genetics. 2009. 73: 540-549.

S. de Friedemann, N. \& Arocha, J. (1985). Herederos del jaguar y la anaconda. Bogotá: Carlos Valencia Editores.

Sánchez, M. C. (2007). Secuenciación de la región control del ADN mitocondrial a partir de fragmentos óseos prehispánicos hallados en el sector de Candelaria La Nueva en Bogotá. Tesis de Maestría. Pontificia Universidad Javeriana. Bogotá, Colombia.

Sandoval, J. A. \& Almanza, O. (2012). Datación de esmalte dental prehispánico proveniente del sitio arqueológico Checua (Cundinamarca) por resonancia paramagnética electrónica (EPR). Revista Colombiana de Física. 44 (3): 248-252.

Santos, F. R., Santos, F. R., Pandya, A., Tyler-Smith, C., Peña, S. D. J., Schanfield, M., Leonard, W. R., Osipova, L., Crawford, M. H., Mitchell, R. J. (2012). The central Siberian origin of native American Y chromosomes. American Journal of Human Genetics. 2012; 64: 619-628.

Sato, M. \& Sato, K. (2013). Maternal inheritance of mitochondrial DNA by diverse mechanisms to eliminate paternal mitochondrial DNA. Biochimica et Biophysica Acta Molecular Cell Research. 1833 (8): 1979-1984.

Shurr, T. G., Ballinger, S. W., Gan, Y.Y., Hodge, J.A., Merriwether, D. A., Lawrence, D. N., Knowler, W. C., Weiss, K. M., Wallace, D. C. (1990). Amerindian mitochondrial DNAs have rare Asian mutations at high frequencies, suggesting they derived from four primary maternal lineages. American Journal of Human Genetics. 46: 613-623.

Silva, A., Briceño, I., Burgos, J., Torres, D., Villegas, V., Gómez, A., Bernal, J. E., Rodríguez, J. V. (2008). Análisis de ADN mitocondrial en una muestra de restos óseos arcaicos del período Herrera de la Sabana de Bogotá. Biomédica. 28: $569-577$.

Sotomayor-Tribín, H. A. \& Cuéllar-Montoya, Z. (2007). Aproximaciones a la paleopatología en América Latina. Bogotá: Convenio Andrés Bello - Academia Nacional de Medicina de Colombia.

Tamm, E. Kivisild, T., Reidla, M., Metspalu, M., Smith, D. G., Mulligan, C. J., Bravi, C. M., Rickards, O., MartínezLabarga, C., Khusnutdinova, E. K., Fedorova, S. A., Golubenko, M. V., Stepanov, V. A., Gubina, M. A., Zhadanov, S. I., Ossipova, L. P., Damba, L., Voevoda, M. I., Dipierri, J. E., Villems, R., Malhi, R. A. (2007). Beringian standstill and spread of native American founders. PLoS One. 2 (9): e829.

Torroni, A., Shurr, T. G., Yang, C. C., Szathmary, E. J. Williams, R. C., Schanfield, M. S., Troup, G. A. Knowler, W. C., Lawrence, D. N., Weiss, K. M. (1992). Native American mitochondrial DNA analysis indicates that the Amerind and the Nadene population were founded by two independent migrations. Genetics. 130: 153-162.

Torroni, A., Shurr, T. G., Cabell, M. F., Brown, M. D., Neel, J. V., Larsen, M., Smith, D. G., Vullo, C. M., Wallace, D. C. (1993). Asian affinities and Continental radiation of the four founding Native American mtDNAs. American Journal of Human Genetics. 53: 563-590.

Van Oven, M. \& Kayser, M. (2008). Updated comprehensive phylogenetic tree of global human mitochondrial DNA variation. Human Mutation. 30 (2): E386-E394.

Wang, S., Lewis Jr., C. M., Jakobsson, M., Ramachandran, S., Ray, N., Bedoya, G., Rojas, W., Parra, M. V., Molina, J. A., Gallo, C., Mazzotti, G., Poletti, G., Hill, K., Hurtado, A. M., Labuda, D., Klitz, W., Barrantes, R., Bortolini, M. C., Salzano, F. M., Petzl-Erler, M. L., Tsuneto, M. L., Llop, E., Rothhammer, F., Excoffier, L., Feldman, M. W., Rosenberg, N. A., Ruiz-Linares, A. (2008). The phylogeny of the four pan-American mtDNA haplogroups: Implications for evolutionary and disease studies. PLoS Genetics. 3 (11): e185. 